\title{
4
}

\section{Medical Assessment and Preparation of Patients Undergoing Bariatric Surgery}

\author{
Wen Bun Leong ${ }^{1}$ and Shahrad Taheri ${ }^{2}$ \\ ${ }^{1}$ Specialist Registrar in Diabetes and Endocrinology and Honorary Research Fellow, \\ Heart of England NHS Foundation Trust, University of Birmingham, \\ ${ }^{2}$ Senior Lecturer and Consultant Physician, Lead in Weight Management, \\ Co-Director Heartlands Biomedical Research Centre, \\ Heart of England NHS Foundation Trust, University of Birmingham,
} $U K$

\section{Introduction}

Bariatric surgery is an important option for patients with extreme obesity and comorbidities. Bariatric surgery, however, has risks and complications involved. Obesity is associated with many health related complications such as cardiovascular disease, type 2 diabetes mellitus, dyslipidaemia, hypertension, and obstructive sleep apnoea (Avenell, Broom et al. 2004; Tsigos, Hainer et al. 2008; Mechanick, Kushner et al. 2009; Scottish Intercollegiate Guidelines and Scotland 2010). It is important to prepare patients to be at their best medical status prior to surgery to prevent adverse outcomes (Mechanick, Kushner et al. 2009). Detailed medical, nutritional and psychological assessments are crucial to improve patients' outcomes post surgery. This usually involves a multidisciplinary team working hand in hand with individual patients guiding them through the whole process as well as continuing lifelong follow up care. A multidisciplinary team usually includes a physician with interest in metabolism, nutrition and bariatric medicine, dietitian with special interest in obesity, a bariatric surgeon, a bariatric specialist nurse and psychologist, and finally a bariatric coordinator (Mechanick, Kushner et al. 2009). Additional expertise includes a psychiatrist, endocrinologist, sleep medicine specialist, cardiologist, gastroenterologist, physician nutrition specialist and certified nutrition support clinician (Mechanick, Kushner et al. 2009). However, the most important factor in the entire process is the individual patient and therefore it is important to individualise each patient's care. Good medical assessment with appropriate information provided for patients will help ease progress through bariatric surgery.

\section{Patients' motivation and expectations}

Patients undergo bariatric surgical procedures for different reasons. It is important to understand each patient's expectations prior to surgery. Studies have shown improvements in psychological or physical health, better quality of life and self esteem as well as better emotional satisfaction in relation with food post operatively (Wolfe and Terry 2006). 
However, there is no gain in romantic and professional relationships post surgery (Wolfe and Terry 2006) and patients should be warned and be prepared for this.

Bariatric surgery offers reduction in body weight of between 20-32\% within 2 years and between $10-25 \%$ after 10 year (Sjostrom, Narbro et al. 2007), or a reduction of $55.9 \%$ in excess weight within 2 years(Buchwald, Estok et al. 2009). Studies have shown of the discrepancies in opinion between medical professionals of a successful surgical outcome and patients' expectations (Foster, Wadden et al. 2001; Wee, Jones et al. 2006; Mechanick, Kushner et al. 2009; Heinberg, Keating et al. 2010). One study showed that the average patient 'dream' weight loss is $55 \mathrm{~kg}$, attributing to $94 \%$ of excess weight loss or losing $43 \%$ of their presurgical weight. About $90 \%$ of the patients in the study were willing to risk death in order achieve their 'dream' weight and almost all patients were willing to risk dying to have a perfect health and their 'dream' weight (Wee, Jones et al. 2006). Younger, Caucasian females with higher body mass index are more likely to have unrealistic expectations (Heinberg, Keating et al. 2010). The team will need to work with patients and provide clear understanding and information regarding realistic outcomes (Tsigos, Hainer et al. 2008) prior to surgery. The team will need to work with patients to negotiate achievable end points and set small feasible goals during the short term period. Providing good education and developing good relationships with patients are vital as this enhances compliance in the future.

Apart from patients' expectation, patients' attitude towards weight loss is also important. It has been shown that 2 years post bariatric surgery, dietary changes and physical activity become lax and patients start to gain weight (Sjostrom, Lindroos et al. 2004). The team will need to assess their likelihood and willingness to make life long changes in their eating habits and engagement in physical activities (National Heart, Blood et al. 1998; UK 2007; Tsigos, Hainer et al. 2008; Scottish Intercollegiate Guidelines and Scotland 2010) to prevent further weight gain pre or post surgery. Motivation could change over time due to various influences (UK 2007). Understanding the medical consequences of obesity will help motivate patients. Other areas to assess motivation are the likelihood to attend follow up appointments, potential barriers to initiate weight loss such as lack of self esteem or confidence in themselves and potential support from family and friends (National Heart, Blood et al. 1998).

\section{Medical assessment}

\subsection{Clinic set up}

Clinic set up is important to provide a safe and friendly environment for patients. Entrances and rooms should be spacious enough for bariatric wheel chair access. Chairs in the waiting area and in clinic rooms should provide armless bariatric chair (Mechanick, Kushner et al. 2009). Wheelchairs availability in hospital should accommodate both the weight and size of patients (Barr and Cunneen 2001). Other essential patient care equipments such as suitable examination table in the clinic room, appropriate weighing scales and stadiometer should be available (Mechanick, Kushner et al. 2009). Facilities such as toilets should not be overlooked and fixtures to help individuals with mobility problems may need to be adapted for bariatric patients (Barr and Cunneen 2001). 


\subsection{Medical history}

A thorough medical history and good physical examination will help identify potential health problems. The most important history will be the patient's eating behaviour covering their history of weight gain and previous attempts for weight loss (Tsigos, Hainer et al. 2008; Mechanick, Kushner et al. 2009). History of weight gain, detailed food history and amount of physical activity is also important. Onset of weight gain could be a consequence of various factors including marriage, pregnancy, and smoking cessation, stress or drug induced. Eating patterns and dietary habits are useful to help exclude eating disorders (Tsigos, Hainer et al. 2008) and this will be covered in the nutritional and psychological section.

History should be holistic, including respiratory, cardiovascular, neurological, gastrointestinal, endocrine, musculoskeletal and genital urinary systems including sexual history. Medication and drug histories are also important as many drugs causes weight gain. It is also important to include usage of illegal drugs and over the counter medication. All past medical history must include mood disorders or other mental health illness (Mechanick, Kushner et al. 2009) as well as family history.

Apart from medical history, it is also essential to obtain the patient's functional status including activities of daily living. It is also important to ask about social history including support available either by family members or friends if patient is deemed suitable for surgery (Mechanick, Kushner et al. 2009). Occupation, alcohol and smoking histories should not be missed (Mechanick, Kushner et al. 2009). The patient should be advised to stop smoking but this should be monitored closely as quitting smoking is associated with weight gain. This holistic approach will paint a better picture of how obesity is affecting the patient. Patients with excessive alcohol intake need to be advised to return to recommended levels.

\subsection{Physical examination}

Physical examination should be thorough including all anthropometric measurement of height and weight to obtain body mass index (Mechanick, Kushner et al. 2009), and waist circumference. Cardiovascular, respiratory, neurology and abdominal systems should be assessed. Neck circumference is an important assessment for obstructive sleep apnoea (Scottish Intercollegiate Guidelines 2003; Epstein, Kristo et al. 2009). Acanthosis nigricans is a sign for insulin resistance (Tsigos, Hainer et al. 2008; Mechanick, Kushner et al. 2009). Other signs include striae distensae (stretch mark), lymphoedema, stasis pigmentation of the lower limbs, intertrigo, hidradenitis suppurativa and acrochordon (Mechanick, Kushner et al. 2009). In patients with history of uncontrolled hypertension and insulin resistance, Cushing's syndrome should be excluded. Signs of Cushing's syndrome are moon facies, posterior cervical fat pads, easy bruisability and purple striae on the abdomen. These signs are, however, rarely seen in clinical bariatric practice.

\subsection{Investigations}

All patients should have routine blood tests to screen for any potential health problems and treat accordingly prior to surgery (Mechanick, Kushner et al. 2009). 
- $\quad$ Full blood count

- Renal function

- $\quad$ Liver function test

- Coagulation profile

- Fasting glucose

- $\mathrm{HbA} 1_{\mathrm{c}}$

- Fasting lipid profile

- Urine pregnancy test
Anaemia

Kidney disease, hypo or hyperkalaemia

Hepatitis, non alcoholic induced fatty liver (see lower section)

Coagulopathy, bleeding disorder

Diabetes mellitus (see lower section)

Diabetes mellitus (see lower section)

Dyslipidaemia

Pregnancy

If secondary causes of obesity are suspected, patient should be evaluated for primary endocrine disorder such as hypothyroidism and Cushing's syndrome (Tsigos, Hainer et al. 2008; Mechanick, Kushner et al. 2009). Screening tests for these are as below (Mechanick, Kushner et al. 2009):

- Hypothyroidism

- Cushing's syndrome

\author{
Thyroid function test \\ Bedtime salivary cortisol level or \\ $1 \mathrm{mg}$ low dose dexamethasone suppression test or \\ 24 hour urine cortisol excretion
}

Interpretation of tests for Cushing's syndrome can be difficult and more detailed tests may be required. There is no indication for routine testing in this patient population. Only patients with indicative signs, history (including relevant metabolic and cardiovascular abnormalities) and where there is an inability to lose weight despite maximal effort, should be investigated.

Any patients undergoing malabsorptive procedure should have their micronutrients status checked prior to surgery and any deficiencies should be corrected (Mechanick, Kushner et al. 2009). If there is an indication of celiac disease based on these investigations, specific coeliac disease investigations should be carried out.

- Iron status Iron deficiency anaemia

(total iron binding capacity, ferritin, iron, transferring receptor)

- Vitamin $B_{12}$ level

- 25-OH Vitamin D

Pernicious anaemia, Vitamin $B_{12}$ deficiency

- $\quad$ Parathyroid hormone (PTH)

- Folate levels

- Bone profile

- Magnesium

Vitamin D deficiency

Vitamin D deficiency

Folic acid deficiency, hyperhomocysteinaemia

Hypocalcaemia, hypophosphataemia

Hypomagnesaemia

Testing for PTH can be costly and should only be undertaken if there are indications based on other test results.

\section{Review of systems}

\subsection{Respiratory status}

Chest $\mathrm{x}$-ray has been recommended to be done for all patients to exclude any pulmonary disorders (Mechanick, Kushner et al. 2009). Chest X-ray, and indeed any imaging 
investigations are difficult to conduct and interpret in this patient population and may not provide any additional information. Any patients with previous history of respiratory disorder should have arterial blood gas and undergo pulmonary function tests (Mechanick, Kushner et al. 2009). Arterial gases are also useful for assessment of the obesity hypoventilation syndrome. Advising patient to quit smoking will help reduce peri-operative respiratory complications (Mechanick, Kushner et al. 2009).

\subsubsection{Lung function in obesity}

Breathlessness is a very common symptom among obese patients. It is shown that obesity could affect respiratory physiology including reduction in respiratory compliance and respiratory muscle strength (McClean, Kee et al. 2008; Sood 2009). In fact, many obese patients have problems with their respiratory function. If cardiac causes have been excluded and the patient is complaining of breathlessness, lung function and exercise tests are useful investigations to assess and rule out other significant respiratory problems such as chronic obstructive airway disease or asthma.

At baseline, pulmonary function tests are different between an obese patient and one with normal body mass index. The most significant difference in an obese patient is the reduction in functional residual capacity (FRC) and expiratory reserve volume (ERV) (Gibson 2000; Jones and Nzekwu 2006; Sood 2009). The higher the body mass index, the greater the effect of reduction (Jones and Nzekwu 2006) hence increasing the work of breathing at rest leading to dyspnoea. This can be explained by the effects of abdominal distension from visceral fat on the diaphragm (Gibson 2000; Rabec, de Lucas Ramos et al. 2011) as well as the reduction in chest wall distensibility (Jones and Nzekwu 2006; Rabec, de Lucas Ramos et al. 2011). There may also be an association in the reduction of forced expiratory volume in 1 second $\left(\mathrm{FEV}_{1}\right)$ (McClean, Kee et al. 2008; Sood 2009; Rabec, de Lucas Ramos et al. 2011).

\subsubsection{Obstructive sleep apnoea (OSA)}

Obstructive sleep apnoea (OSA) is a condition characterised by episodic complete or partial obstruction of the upper airway during sleep (Rabec, de Lucas Ramos et al. 2011). Obesity is one of the major risk factor for developing OSA. There is an increased in subcutaneous and periluminal fat causing narrowing of the pharynx leading to obstruction (Epstein, Kristo et al. 2009). This could cause difficulties during peri-operative airway management (Mechanick, Kushner et al. 2009) and presence of OSA has been shown in LABS study to increase 30 day operative mortality (Flum, Belle et al. 2009) hence the importance of the diagnosis leading to more stringent perioperative care of these individuals. About $40 \%$ of obese patients suffer with OSA (Sood 2009) and the prevalence can be as high as $98 \%$ in the morbidly obese patients (Valencia-Flores, Orea et al. 2000).

Excessive daytime somnolence, snoring at night, feeling unrefreshed on waking, restless sleep, impaired concentration, irritability and apnoeic episodes during sleep are some of the common symptoms of OSA. It has been recommended that all obese patients should be assessed to exclude OSA either by respiratory physician or use the validated questionnaires such as the Epworth's Sleepiness Score (ESS) (Johns 1991) or the Berlin Questionnaire (Netzer, Stoohs et al. 1999) The ESS should be completed by both the patient and the partner if possible. ESS has a maximum score of 24 and a score of $>18$ is suggestive of severe 
subjective daytime somnolence, score of between 15 and 18 is moderate while score of between 11 and 14 is mild (Scottish Intercollegiate Guidelines 2003). Berlin questionnaire looked at 3 different categories; which are snoring, wake time sleepiness or drowsy driving and hypertension or obesity. High risk for OSA is defined as persistent symptoms in at least 2 of the categories with a sensitivity of $86 \%$ and specificity of $77 \%$ (Netzer, Stoohs et al. 1999). In our experience, the Berlin and Epworth questionnaires are not good indicators of OSA and we recommend formal evaluation for OSA in all bariatric patients.

All patients should undergo sleep studies depending on facilities available. Polysomnography is the investigation of choice to assess OSA and it consists of electroencephalogram (EEG), electroculogram (EOG), chin electromyogram, oxygen saturation, respiratory airflow, thoracic movements and electrocardiography (ECG) (Scottish Intercollegiate Guidelines 2003; Epstein, Kristo et al. 2009). Body position and snoring is monitored as well (Scottish Intercollegiate Guidelines 2003; Epstein, Kristo et al. 2009). Overnight monitoring is ideal and results will then be interpreted. If a full polysomnography is not available, then the sleep study usually consists of respiratory assessment, thoraco-abdominal movement, and monitor for snoring episodes (Scottish Intercollegiate Guidelines 2003). In-laboratory polysomnography may not be routinely available to all patients due to high cost and technical complexity (Collop, Anderson et al. 2007). In that case, unattended portable monitors could be alternative choice. American Academy of Sleep Medicine guideline stated the use of portable monitors should be 'in conjunction with a comprehensive sleep evaluation' for 'patients with high pretest probability of or moderate to severe OSA' who do not have significant co-morbidies such as severe pulmonary disease, neuromuscular disease or congestive heart failure (Collop, Anderson et al. 2007).

The aim of polysomnography is to measure apnoea or hypopnoea episodes. These episodes are reported as apnoea/hypopnoea index (AHI) or respiratory disturbance index (RDI) and can be divided into (Scottish Intercollegiate Guidelines 2003; Epstein, Kristo et al. 2009):

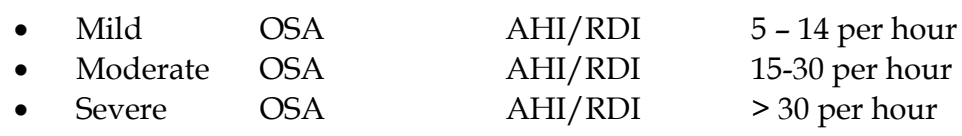

Treatment for OSA is weight reduction hence bariatric surgery could help the condition. Non surgical treatment of OSA includes continuous positive airway pressures. Positive airway pressure can be continuous (CPAP), autotitrating (APAP) or bilevel (BPAP) (Scottish Intercollegiate Guidelines 2003; Epstein, Kristo et al. 2009). Sedatives and alcohol should be avoided in the evenings and at night as they reduce airway dilator function hence worsening of OSA (Scottish Intercollegiate Guidelines 2003). Post-operatively, these patients need to be monitored closely and to continue to use their positive airway pressure appliances (Mechanick, Kushner et al. 2009). There is debate regarding duration of CPAP use prior to operation (some centres recommending 3 months), peri-operatively (theoretical potential to disturb anastomoses in non gastric band operations), and post-operatively.

\subsubsection{Obesity hypoventilation syndrome (OHS)}

Obesity hypoventilation syndrome is a diagnosis of exclusion. The definition of OHS is a condition of consists of daytime hypercapnia and hypoxemia, sleep disordered breathing 
and obese patient (Mokhlesi 2010). The majority of OHS patients will also have OSA. Other respiratory conditions including intrinsic respiratory disorders, central hypoventilation syndromes and neuromuscular disorders should be excluded (Mokhlesi, Kryger et al. 2008).

Clinical features of OHS are similar to OSA consisting of hypersomnia and headache when awake, snoring and disturbed sleep (Casey, Cantillo et al. 2007). Pathogenesis is likely to be multifactorial. Reduction in respiratory compliance and lung volume, effects of leptin on central ventilatory drive, inspiratory muscle fatigue and depressed central ventilator control from sleep disturbances and raised $\mathrm{PaCO} 2$ on central ventilation are likely to play a role in this condition (Casey, Cantillo et al. 2007). Non-invasive positive pressure ventilation is effective and well tolerated in treating this condition (Mokhlesi and Tulaimat 2007; Priou, Hamel et al. 2010).

\subsubsection{Smoking}

Smoking causes adverse effects on health. The most common respiratory diseases associated with smoking are increased risk of chronic obstructive pulmonary disease and bronchogenic carcinoma. Smoking also increases risk of cardiovascular disease leading to myocardial infarction and peripheral vascular disease. Obese patients are already at higher risk of developing various health problems so these patients should be encouraged and assisted to stop smoking to help improve life expectancy (Scottish Intercollegiate Guidelines and Scotland 2010). It is recommended that patients should quit smoking at least 8 weeks prior to surgery to help reduce risk of respiratory complications (Mechanick, Kushner et al. 2009). Unfortunately, smoking cessation is associated with weight gain (Williamson, Madans et al. 1991; Flegal, Troiano et al. 1995; Wise, Enright et al. 1998; Scottish Intercollegiate Guidelines and Scotland 2010) and patients might be reluctant to quit (McClean, Kee et al. 2008).

Weight gain from smoking cessation is more pronounced in females compared to males (Williamson, Madans et al. 1991; Wise, Enright et al. 1998). Mean weight gain is between $2.8 \mathrm{~kg}$ (Williamson, Madans et al. 1991) to 5kg (Flegal, Troiano et al. 1995; Wise, Enright et al. 1998) with females gaining approximately $1 \mathrm{~kg}$ more than males (Williamson, Madans et al. 1991). A proportion of patients will gain more than $13 \mathrm{~kg}$ in weight (Williamson, Madans et al. 1991). Weight gain from quitting smoking has been associated with increased in prevalence in overweight population (Flegal, Troiano et al. 1995) and this could lead to obesity in the future. Although there is risk of weight gain, the benefits from smoking cessation is greater in improvement in lung function in particular $\mathrm{FEV}_{1}$ and FVC (Wise, Enright et al. 1998). The Framingham Heart Study found that obese smokers have almost doubled the reduction in life expectancy as compared to obese non smokers (Peeters, Barendregt et al. 2003).

Patient should be given advice to seek help for smoking cessation. The reasons for weight gain might be due to various mechanisms. An increased in food consumption (2010) of up to 250 to 300 kilocalories a day after stopping smoking, reduction in physical activity (Chiolero, Faeh et al. 2008), changes in fat metabolism e.g. lipoprotein activity (Williamson, Madans et al. 1991; Chiolero, Faeh et al. 2008) and changes in insulin homeostasis (Williamson, Madans et al. 1991) could all contribute to weight gain. Patients should be advised have low calorie diet, reduce in portion sizes during meal times and avoid second 
helpings (2008). Chewing gum or nicotine gum helps to prevent snacking. Dietary advice on healthy balanced diet and increase in physical activities, getting new hobbies to relieve boredom are some simple advice for patients to stop smoking (2008). Individualised treatment plan with dietary and cognitive behavioural intervention will help potential quitters prevent weight gain (Scottish Intercollegiate Guidelines and Scotland 2010). Buproprion helps with weight loss (Davtyan and Ma 2008) and this could be use along side with nicotine replacement therapy. Smokers tend to have a longer hospital stay and smoking cessation should be recommended well in advance of bariatric surgery.

\subsection{Cardiovascular status}

Obesity increases risk for cardiovascular disorder (Hubert, Feinleib et al. 1983; Jonsson, Hedblad et al. 2002; Wilson, D'Agostino et al. 2002; Wolk, Berger et al. 2003) and premature death (Jonsson, Hedblad et al. 2002; Peeters, Barendregt et al. 2003) but is not a risk factor for post-operative cardiac complication (Mechanick, Kushner et al. 2009). Blood pressure monitoring to assess for hypertension and electrocardiography are basic investigations to assess cardiovascular function. Cardiac sounding chest pain or angina episodes should be investigated further, but investigations are limited given body habitus and lack of resolution of diagnostic tests. Difficulties lie with patient complaining of dyspnoea as this could present as cardiac disease or obesity related dyspnoea. Exercise tolerance will be useful to assess cardiac risk. Presence of other metabolic risk factors especially diabetes mellitus increases the patient's risk for coronary artery disease (Fox, Coady et al. 2007).

\subsubsection{Electrocardiogram (ECG)}

Obesity may cause changes in ECG readings. Some common changes include left axis deviation likely due to displacement of the heart from raised diaphragm due to abdominal visceral fat and small voltages (Eisenstein, Edelstein et al. 1982; Frank, Colliver et al. 1986; Alpert, Terry et al. 2000; Poirier, Giles et al. 2006) from the increased distance between the heart and the chest wall (Poirier, Giles et al. 2006). Cardiac work load is also increased (Lavie, Milani et al. 2009) and this could lead to left ventricular hypertrophy (Lauer, Anderson et al. 1991; Poirier, Giles et al. 2006; Avelar, Cloward et al. 2007; Lavie, Milani et al. 2009; Movahed, Martinez et al. 2009). Pulmonary diseases such as obstructive sleep apnoea could cause cor pulmonale changes. Other possible ECG changes are increased in heart rate (Frank, Colliver et al. 1986; Poirier, Giles et al. 2006), prolonged PR interval (Frank, Colliver et al. 1986; Poirier, Giles et al. 2006; Seyfeli, Duru et al. 2006), prolonged QRS interval (Frank, Colliver et al. 1986; Poirier, Giles et al. 2006), prolonged QTc interval (Frank, Colliver et al. 1986; Alpert, Terry et al. 2000; Pontiroli, Pizzocri et al. 2004; Poirier, Giles et al. 2006; Arslan, Yiginer et al. 2010), ST-T wave abnormalities (Frank, Colliver et al. 1986; Poirier, Giles et al. 2006) and flattening of the T wave especially in the inferolateral leads (Eisenstein, Edelstein et al. 1982; Alpert, Terry et al. 2000; Lopez-Jimenez and CortesBergoderi 2011).

\subsubsection{Echocardiography}

Technical difficulty in echocardiography is common in obese patients due to the size as well as the distance between chest wall and heart. Obesity increases the risk of left ventricular hypertrophy (LVH) (Lauer, Anderson et al. 1991; de la Maza, Estevez et al. 1994; Poirier, 
Giles et al. 2006; Avelar, Cloward et al. 2007; Lavie, Milani et al. 2009; Movahed, Martinez et al. 2009) and this could be assessed using echocardiography. Presence of LVH increase risk of mortality as it is associated with coronary heart disease and stroke(Benjamin and Levy 1999). Other potential abnormality include left atrial enlargement (Lavie, Milani et al. 2009; Arslan, Yiginer et al. 2010), difficulty in the assessment of pericardial fluid due to thickened epicardial tissue (Poirier, Giles et al. 2006). Dobutamine stress echocardiography is probably more useful than conventional echocardiogram to assess cardiac function (Mechanick, Kushner et al. 2009).

\subsubsection{Hypertension}

Hypertension is a well-recognised risk factor for coronary artery disease (Kannel 1996; Diaz 2002; I 2010). Prevalence of hypertension is higher among overweight and obese population(Stamler, Stamler et al. 1978; Brown, Higgins et al. 2000) and is not associated with ethnicity or socioeconomic status (Diaz 2002). Indeed, increased in visceral abdominal fat in obesity increases the risk of hypertension (Narkiewicz 2006). Uncontrolled hypertension with blood pressure levels above 180/110 $\mathrm{mmHg}$ should be corrected as this could lead to perioperative ischaemic events (Mechanick, Kushner et al. 2009).

Many mechanisms have been postulated for the causation of hypertension and this includes changes in substances released from adipose tissue (Benjamin and Levy 1999; I 2010), increased in sympathetic activity (Narkiewicz 2006; Poirier, Giles et al. 2006, Wilcox 2010) and presence of obstructive sleep apnoea (Diaz 2002; Avelar, Cloward et al. 2007). Increase in body weight leads to increase in sympathetic activity (Narkiewicz 2006; Poirier, Giles et al. 2006; Wilcox 2010); and this could be explained by the activation of renin-angiotensinaldosterone system (Narkiewicz 2006; Wilcox 2010). Hypoxaemia and hypercapnic episodes as well as changes in the intrathoracic pressure in obstructive sleep apnoea has been found to increase blood pressure (Diaz 2002; Avelar, Cloward et al. 2007).

Adipose tissue releases several adipokines (Maenhaut and Van de Voorde 2011). One adipokine is the hormone leptin (Wilcox 2010; Maenhaut and Can de Voorde 2011). Leptin levels are elevated in hypertension and its effect could be via the activation of the sympathetic nervous system or dysfunction of the endothelium causing vasoconstriction leading to increase in peripheral vascular resistance (Maenhaut and Van de Voorde 2011).

Apart from increased risk in coronary heart disease, hypertension also increases the risk of developing renal failure (Narkiewicz 2006; Wilcox 2010). It is important to treat this condition vigilantly to prevent perioperative ischaemic event (Mechanick, Kushner et al. 2009). Many guidelines are available as references for the treatment of hypertension such as the JNC VII report (Chobanian, Bakris et al. 2003) and British Hypertension Society guidelines (Williams, Poulter et al. 2004).

\subsubsection{Coronary heart disease}

Obesity increases the risk of myocardial infarction and coronary heart disease and is an independent risk factor for cardiovascular disease (Hubert, Feinleib et al. 1983; Wilson, D'Agostino et al. 2002). Given that there is increasing prevalence in hypertensive patients and obesity related obstructive sleep apnoea as well as increased risk of dyslipidaemia 
and insulin resistance, these factors most likely contribute to the cumulative risks for obese patients (Poirier, Giles et al. 2006; Lopez-Jimenez and Cortes-Bergoderi 2011). Apart from this, it has been found that in young men, obesity could accelerate the development of atherosclerosis (McGill, McMahan et al. 2002). Patients with cardiac sounding chest pain or any previous history of cardiac disease should not be taken lightly prior to surgery and should be investigated thoroughly by a cardiologist and treated accordingly to minimise risk during surgery. Prophylactic beta-blocker therapy has been recommended for patients who have high risk of cardiac disease (Mechanick, Kushner et al. 2009).

\subsection{Metabolic control}

A high proportion of patients with obesity suffer from metabolic syndrome. Diagnosis of metabolic syndrome is based on the presence of insulin resistance, obesity, dyslipidaemia, and hypertension. Both International Diabetes Federation (IDF) (Alberti, Zimmet et al. 2005) and National Cholesterol Education Program Adult Treatment Panel (NCEP ATP III)(2002) have their own criteria for metabolic syndrome as summarized below:

\begin{tabular}{|c|c|c|c|c|}
\hline & Obesity & Lipid & Blood pressure & Glucose \\
\hline $\begin{array}{l}\text { IDF - } \\
\text { Obesity } \\
\text { plus } 2 \\
\text { factors }\end{array}$ & $\begin{array}{l}\text { Waist circumference } \\
\text { (ethnic specific) } \\
>94 \mathrm{~cm}(\mathrm{M}) \text { or } \\
>80 \mathrm{~cm}(\mathrm{~F})\end{array}$ & $\begin{array}{l}\text { Raised } \mathrm{Tg} \geq 150 \mathrm{mg} / \mathrm{dl} \\
\text { or } \\
\mathrm{HDL}<50(\mathrm{M}) \\
\text { or } \\
<40 \mathrm{mg} / \mathrm{dl}(\mathrm{F}) \\
\text { or on therapy }\end{array}$ & $\begin{array}{l}\geq 130 / 85 \\
\mathrm{mmHg} \\
\text { or on therapy }\end{array}$ & $\begin{array}{l}\text { Fasting glucose } \\
>100 \mathrm{mg} / \mathrm{dl} \\
\text { or known } \\
\text { diabetes } \\
\text { mellitus }\end{array}$ \\
\hline $\begin{array}{l}\text { NCEP } \\
\text { ATP III } \\
\text {-any } 3 \\
\text { criteria }\end{array}$ & $\begin{array}{l}\text { Waist circumference } \\
>102 \mathrm{~cm} / 40 \text { inches }(\mathrm{M}) \\
\text { or } \\
>88 \mathrm{~cm} / 35 \text { inches }(\mathrm{F})\end{array}$ & $\begin{array}{l}\text { Raised Tg } \geq 150 \mathrm{mg} / \mathrm{dl} \\
\text { or } \\
\text { HDL }<40 \mathrm{mg} / \mathrm{dl}(\mathrm{M}) \\
\text { or } \\
<50 \mathrm{mg} / \mathrm{dl}(\mathrm{F}) \\
\text { or on therapy }\end{array}$ & $\begin{array}{l}\geq 130 / 85 \mathrm{mmHg} \\
\text { or on therapy }\end{array}$ & $\begin{array}{l}\text { Fasting glucose } \\
>110 \mathrm{mg} / \mathrm{dl} \\
\text { or known } \\
\text { diabetes } \\
\text { mellitus }\end{array}$ \\
\hline
\end{tabular}

M=Male; F=Female

Table 1. Criteria for metabolic syndrome

\subsubsection{Diabetes mellitus}

Obesity can cause insulin resistance due to changes in adipokines, inflammatory mechanisms and intrinsic cell mechanisms (Qatanani and Lazar 2007). Insulin resistance could in turn lead to development of diabetes mellitus (Chan, Rimm et al. 1994; KohBanerjee, Wang et al. 2004). Raised visceral or waist to hip ratios (Chan, Rimm et al. 1994; Koh-Banerjee, Wang et al. 2004) and duration of obesity (Wannamethee and Shaper 1999) are good predictors of diabetes mellitus. Many individuals might already have diagnoses of diabetes mellitus and the rest needs to be screened with either fasting plasma glucose, $\mathrm{HbA}_{\mathrm{c}}$ or a formal oral glucose tolerance test.

Diagnosis of diabetes could be made by the presence of either one of the following based on the American Diabetes Association criteria (ADA) (2011): 
- $\quad H b A 1_{c} \geq 48 \mathrm{mmol} / \mathrm{mol}$ or $6.5 \%$

- $\quad$ Fasting plasma glucose $\geq 126 \mathrm{mg} / \mathrm{dl}$ or $7.0 \mathrm{mmol} / 1$

- Oral glucose tolerance test after $75 \mathrm{~g}$ of oral glucose with a result of fasting plasma glucose of $\geq 126 \mathrm{mg} / \mathrm{dl}$ or $7.0 \mathrm{mmol} / 1$ or 2 hour post-prandial reading of $\geq 200 \mathrm{mg} / \mathrm{dl}$ or $11.1 \mathrm{mmol} / 1$.

- Random plasma glucose of $\geq 200 \mathrm{mg} / \mathrm{dl}$ or $11.1 \mathrm{mmol} / 1$ with classical symptoms of hyperglycaemia or hyperglycaemia crisis such as hyperglycaemic hyperosmolar state or diabetic ketoacidosis.

Newly diagnosed patients with diabetes mellitus should be managed appropriately. Lifestyle measures are usually the first step (Nathan, Buse et al. 2009; National Institute for et al. 2009). ADA and European Association of Study of Diabetes (EASD) (Nathan, Buse et al. 2009) as well as National Institute for Health and Clinical Excellence (NICE) (2009) have published guidelines for the management of type 2 diabetes mellitus. There are various different medications for diabetes mellitus and are associated with their own adverse effects including drug induced weight gain (Makimattila, Nikkila et al. 1999). A summary of the medications with effects on $\mathrm{HbA} 1_{c}$, weight and adverse effects is as below (Nathan, Buse et al. 2009; Dicker 2011):

\begin{tabular}{|l|c|l|l|}
\hline Anti-diabetic medications & $\begin{array}{l}\text { Reduction in } \\
\text { HbA1 }(\%)\end{array}$ & $\begin{array}{l}\text { Effects on } \\
\text { weight }\end{array}$ & Other adverse side effects \\
\hline $\begin{array}{l}\text { Biguanides } \\
\text { Eg. Metformin }\end{array}$ & $1.0-2.0$ & Weight neutral & $\begin{array}{l}\text { Gastrointestinal side effects, } \\
\text { rarely lactic acidosis }\end{array}$ \\
\hline $\begin{array}{l}\text { Sulphonylureas } \\
\text { Eg. gliclazide, glipizide, } \\
\text { glibenclamide }\end{array}$ & $1.0-2.0$ & Weight gain & Hypoglycaemia \\
\hline $\begin{array}{l}\text { a-glucosidase inhibitors } \\
\text { Eg. Acarbose }\end{array}$ & $0.5-0.8$ & Weight neutral & $\begin{array}{l}\text { Gastrointestinal side } \\
\text { effects }\end{array}$ \\
\hline $\begin{array}{l}\text { Glucagon like peptide (GLP)-1 } \\
\text { Eg. exenatide, liraglutide }\end{array}$ & $0.5-1.0$ & Weight loss & Nausea, vomiting \\
\hline $\begin{array}{l}\text { Pramlintide } \\
\text { Glinides } \\
\text { Eg. repaglinide and nateglinide }\end{array}$ & $0.5-1.5$ & Weight gain & $\begin{array}{l}\text { Gastrointestinal side } \\
\text { effects }\end{array}$ \\
\hline $\begin{array}{l}\text { Insulin } \\
\text { Thiazolidinediones } \\
\text { Eg. pioglitazone, rosiglitazone* }\end{array}$ & $0.5-1.4$ & Weight gain & $\begin{array}{l}\text { Fluid retention, *increased } \\
\text { cardiovascular risk }\end{array}$ \\
\hline $\begin{array}{l}\text { Dipeptidyl peptidase } 4 \text { (DPP-4) } \\
\text { inhibitor(Dicker 2011) } \\
\text { Eg. sitagliptin, saxagliptin, } \\
\text { vildagliptin }\end{array}$ & $0.43-1.4$ & Weight neutral & $\begin{array}{l}\text { Upper respiratory tract } \\
\text { infection, nasopharyngitis, } \\
\text { headache }\end{array}$ \\
\hline
\end{tabular}

* Rosiglitazone is associated with increased cardiovascular risk and is withdrawn in the United Kingdom (2010) and in europe (2010). United States Food and Drug Administration (FDA) have issued restriction on its usage (2011).

Table 2. HbA1c, weight and adverse effects of anti-diabetic medications (Nathan, Buse et al. 2009; Dicker 2011) 
It is recommend to have a $\mathrm{HbA} 1_{\mathrm{c}}$ level of $<53 \mathrm{mmol} / \mathrm{mol}$ or $7.0 \%$ (Mechanick, Kushner et al. 2009; 2011), fasting plasma glucose of $<110 \mathrm{mg} / \mathrm{dl}$ or $6.1 \mathrm{mmol} / 1$ (2011) preoperatively to ensure good outcome. This, however, is unrealistic in many patients who are having bariatric surgery to treat their poor diabetes control. There is a greater propensity for day case and short stay bariatric surgery which allows patients with less well-controlled diabetes to have bariatric surgery.

\subsubsection{Dyslipidaemia}

Increased in visceral adipose tissue in obesity is associated with raised triglyceride levels, raised small dense low density lipoprotein (sdLDL) and reduction in high density lipoprotein cholesterol (HDL) levels (Ginsberg and Maccallum 2009; Athyros, Tziomalos et al. 2011). In addition, presence of insulin resistance as previously described can further increased free fatty acids availability to other organs (Athyros, Tziomalos et al. 2011). Guidelines such as the National Cholesterol Education Program on adult treatment panel III (NCEP ATP III) (2002) and NICE guidelines on lipid modifications (2010) are useful to help treat and reduce cardiovascular risk.

\subsection{Gastrointestinal (GI) status}

Presence of any gastrointestinal (GI) symptoms should warrant further evaluation with additional investigations (Mechanick, Kushner et al. 2009). Gastroenterology referral is appropriate and endoscopy could be performed to rule out serious diseases. It is important to note that obesity is associated with a number of cancers. Physicians should be vigilant to distinguish between healthy planned weight loss and weight loss due to sinister reasons such as cancer.

\subsubsection{Common gastrointestinal problems in obesity}

There appears to be a positive correlation between obesity and gastrointestinal symptoms especially abdominal pain, vomiting and diarrhoea (Delgado-Aros, Locke et al. 2004; Talley, Howell et al. 2004). It is still unclear as to the mechanisms causing these symptoms (Delgado-Aros, Locke et al. 2004; Talley, Howell et al. 2004). Other upper GI symptoms could be caused by gastroesophageal reflux disease (GERD). GERD is a common disorder and patients present with different symptoms including heartburn, acid regurgitation, chest pain, dysphagia and dyspepsia (Locke, Talley et al. 1997). One of the major risk factor for GERD is obesity (El-Serag, Graham et al. 2005; Corley and Kubo 2006). Oesophageal erosions are also more prevalent in obese patients (El-Serag, Graham et al. 2005). This is important as symptomatic GERD is associated with future development of Barrett's oesophagus and oesophageal adenocarcinoma (Lagergren, Bergstrom et al. 1999). Therefore it is important to treat this condition adequately either through medical therapies or weight loss through surgery.

\subsubsection{Gallstones}

Gallstones disease is common in obese population and could cause abnormality in liver enzyme levels. Rapid weight loss post bariatric surgery especially with Roux-en-Y gastric bypass surgery is associated with biliary stasis and lithiasis (Caruana, McCabe et al. 2005; 
Quesada, Kohan et al. 2010). Patients could have concomitant cholecystectomy during surgery with disadvantage of increased in intrasurgical time or treat with prophylactic ursodeoxycholic acid post surgery for 6 months (Quesada, Kohan et al. 2010).

\subsubsection{Non-alcoholic fatty liver disease}

Obesity is one of the major risk factor for non-alcoholic fatty liver disease (NAFLD) (Clain and Lefkowitch 1987; Salgado Junior, Santos et al. 2006; Scaglioni, Ciccia et al. 2011) and is often asymptomatic (Salgado Junior, Santos et al. 2006). Abnormal liver function test results especially with raised aspartate transaminase (AST) and AST/ALT (alanine transaminase) ratio are some predictors of this disease (Liew, Lee et al. 2006; Salgado Junior, Santos et al. 2006). Viral, autoimmune and other rare causes such as Wilson's disease and alpha-1 antitrypsin deficiency should be ruled out in the presence of abnormal test results. Other laboratory abnormalities are raised $\gamma$ - glutamyltransferease ( $\gamma \mathrm{GT})$ and alkaline phosphatase (ALP), dyslipidaemia and hyperglycaemia (Salgado Junior, Santos et al. 2006). Liver biopsy is the gold standard for diagnosing this condition (Salgado Junior, Santos et al. 2006; Vuppalanchi and Chalasani 2009). Ultrasound scan of the liver (Mechanick, Kushner et al. 2009) or liver biopsy(Salgado Junior, Santos et al. 2006)is recommended in the presence of 23 folds increased in the liver enzymes. Transient elastography (Lupsor, Badea et al. 2010) including using XL probe for obese patients (Myers, Pomier-Layrargues et al. 2011) is an alternative method in assessing liver stiffness hence able to detect liver fibrosis. Hepatotoxic medications should be avoided in these patients (Salgado Junior, Santos et al. 2006) and bariatric surgery can potentially reverse the condition (Srivastava and Younossi 2005; De Ridder, Schoon et al. 2007; Kaila and Raman 2008).

\subsubsection{Alcohol}

Alcohol is another common cause for abnormal liver function test results and excessive intake could potentially cause liver problems including cirrhosis. In a study, it is found that overweight and obese individuals have higher risk of raised liver enzymes with only 2 alcohol drinks per day (Ruhl and Everhart 2005). Current history of excess alcohol use is contraindicated for bariatric surgery (Snyder 2009) and these patients should be referred to other services to help quit. Patients undergoing bariatric surgery need to be counselled regarding alcohol. Total abstinence is not necessary as in gastric band patients, those who are teetotal appear to lose less weight (Dixon, Dixon et al. 2001). Alcohol absorption is greater in malabsorptive type operations and patients should be warned that there are risks of rapid intoxication and greater liver damage by alcohol.

\subsection{Endocrine disorders causing obesity}

A small proportion of patients' weight problem might be due to endocrine disorders especially for patients with history of recent weight gain. The common disorders include hypothyroidism, Cushing's syndrome and prolactinoma. Hypothyroidism is associated with weight gain through reduction in metabolic rate and thermogenesis (Reinehr 2010). Associations have been found between obesity and thyroid function especially elevation in thyroid stimulating hormone (TSH) (Knudsen, Laurberg et al. 2005; Nyrnes, Jorde et al. 2006). This is likely to help in increasing energy expenditure leading to reduction in fat 
deposition (Reinehr 2010). Furthermore, obesity is associated with reduced tissue conversion of $\mathrm{T} 4$ to $\mathrm{T} 3$. It should be noted that in up to $30 \%$ of patients with thyroid overactivity, weight gain may occur rather than weight loss.

Hyperprolactinaemia could lead to increase in weight as shown in patients with prolactinomas. When prolactin levels fall after treatment so does patients' weight (Greenman, Tordjman et al. 1998). The relationship between prolactin level and weight could be due to the changes within central dopaminergic pathway and reduction in serotonin secretion(Kopelman 2000). Prolactin level has been found to be elevated in obese females (Kok, Roelfsema et al. 2004) and levels falls after weight loss (Kok, Roelfsema et al. 2006). Raised prolactin level in obesity might be a result of hyperinsulinaemic state or alterations in doperminergic and serotoninergic activities centrally (Kopelman 2000).

Cushing's syndrome is a condition of chronic excessive glucocorticoid production. This condition causes weight gain amongst other clinical features as described above. In patients with morbid obesity, mild hypercortisolaemia could be found with increased urinary free cortisol level (Nieman, Biller et al. 2008). Other conditions mimicking Cushing's syndrome are chronic alcoholism, major depressive disorder (Orth 1995), poorly controlled diabetes mellitus, and pregnancy (Nieman, Biller et al. 2008). One should always keep in mind these potential endocrine abnormalities causing obesity and investigate further in suspicious cases.

\subsection{Reproductive status}

In males, increased in BMI is associated with fertility problems (Nguyen, Wilcox et al. 2007) and this could be related to reduction in testosterone, sex hormone binding globulin (SHBG) and free testosterone as weight increases (MacDonald, Herbison et al. 2010). Oestradiol level on the other hand is increased (Hammoud, Gibson et al. 2009) and this is likely caused by aromatisation of adipose tissue. Hormonal changes are likely to cause problems with sexual quality of life and this can be reversed with bariatric surgery (Hammoud, Gibson et al. 2009).

In females, high body mass index could cause problem with menstrual irregularities (Jones, Srinivasan et al. 2007; Wei, Schmidt et al. 2009; Kulie, Slattengren et al. 2011). The underlying cause could be due to polycystic ovarian syndrome, oligomenorrhoea or amenorrhoea (Jones, Srinivasan et al. 2007) leading to issues with ovulation. Links have been found between increased abdominal fat with anovulation (Kuchenbecker, Groen et al. 2010) likely due to insulin resistance (Pasquali, Pelusi et al. 2003). These problems in turn lead to sub- or infertility by disrupting spontaneous ovulation and can reduced efficacy of assisted fertility treatment (Pasquali, Pelusi et al. 2003; Balen 2007; Farquhar 2007; Pasquali, Patton et al. 2007). However, fertility is improved post bariatric surgery due to weight loss (Guelinckx, Devlieger et al. 2009; Shah and Ginsburg 2010; Hezelgrave and Oteng-Ntim 2011; Kulie, Slattengren et al. 2011). Early pregnancy post surgery might be associated with increased risk of miscarriages and possibility of preterm birth (Guelinckx, Devlieger et al. 2009). Therefore, patients suitable for surgery are generally advised not to seek pregnancy at least 1 year after surgery (Guelinckx, Devlieger et al. 2009; Mechanick, Kushner et al. 2009). This is especially important in patients receiving malabsorptive surgeries as there are 
potentially severe nutritional deficiencies that could be exacerbated in pregnancy (Guelinckx, Devlieger et al. 2009; Hezelgrave and Oteng-Ntim 2011).

Contraception advice is vital. Obesity is a risk factor for venous thromboembolism (Stein, Beemath et al. 2005) and can cause recurrent thromboses (Eichinger, Hron et al. 2008). Oestrogen therapy is recommended to be stopped a month prior to surgery to avoid this complication (Mechanick, Kushner et al. 2009). Individuals going for malabsorptive procedures should be advice to avoid oral contraception as post operative as there is a risk of failure to absorb leading to failure of treatment (2010; Paulen, Zapata et al. 2010). There are concerns as well regarding risk of fractures due to effects on bone mineral density from usage of depot medroxyprogesterone acetate (DMPA) after malabsorptive surgery (Paulen, Zapata et al. 2010).

\subsection{Medications causing weight gain}

The commonest cause of weight gain is due to adverse effect from drug therapy and patients should be advised on weight gain when these medications are prescribed (Scottish Intercollegiate Guidelines and Scotland 2010). Common medications causing weight gain are as follows (Kulkarni and Kaur 2001; Ness-Abramof and Apovian 2005; Leslie, Hankey et al. 2007; Davtyan and Ma 2008; Scottish Intercollegiate Guidelines and Scotland 2010; Nihalani, Schwartz et al. 2011):

- Anti-convulsants (sodium valproate, carbamazepine, gabapentin)

- Anti-psychotics (clozapine, olanzapine, risperidone, quetiapine, clopromazine, ziprasidone, aripiprazole)

- Anti-depressants (tricyclic anti-depressants (TCA), selective serotonin reuptake inhibitors (SSRI), mirtazapine)

- Mood stabilisers (lithium)

- Anti-hypertensives (beta blockers, calcium channel blockers)

- Anti-diabetic medications (insulin, sulphonylurea, thiazolidinedione)

- Steroid

- Anti-neoplastic agents (tamoxifen)

- Anti-histamines

Mechanisms of medications causing weight gain could be due to their effects on appetite through receptors at the central nervous system or effects on the body's metabolism. Antihistaminergic effect by most psychotropic medications including anti-depressants and anti-psychotics causes cravings for carbohydrate (Davtyan and Ma 2008; Nihalani, Schwartz et al. 2011). Antipsychotics cause inhibitory effect on serotonin and epinephrine receptors thus stimulating appetite (Davtyan and Ma 2008). These effects could cause 2 to $17 \mathrm{~kg}$ of weight gain during treatment (Nihalani, Schwartz et al. 2011). Lithium is used as mood stabilisers and might cause weight gain through increasing level of serum leptin (Atmaca, Kuloglu et al. 2002) or changes in thyroid function. As many obese patients suffer from depression, medications to treat the condition could be a cause of obesity or exacerbate the problem. Venlafaxine is weight neutral while bupropion causes weight loss so could be treatment of choice if patient is not contraindicated to these medications (Davtyan and Ma 2008). 
Anticonvulsants cause weight gain through the effects on endocrine system and body metabolism. Sodium valproate causes increase in insulin and leptin levels with reduction in gluconeogenesis and metabolic rate (Davtyan and Ma 2008). Alternative medication using weight neutral anticonvulsants such as lamotrigine (Kulkarni and Kaur 2001) and levetiracetam (Davtyan and Ma 2008) could help prevent the problem, and topiramate may help induce weight loss (Kulkarni and Kaur 2001; Davtyan and Ma 2008).

Beta adrenergic receptors are present in adipose tissue and when stimulated by noradrenaline, help to metabolize fat into energy source (Nihalani, Schwartz et al. 2011). Beta blocker not only reverses this effect, it also causes reduction in resting metabolic rate (Davtyan and Ma 2008). Verapamil might cause weight gain through inhibition in dopaminergic receptor while clonidine reduces sympathetic activity via central nervous system thus decreasing the metabolic rate (Davtyan and Ma 2008). Angiotensin converting enzyme (ACE) inhibitors and diuretics are other possibilities as treatment for hypertension (Davtyan and Ma 2008).

Obesity is associated with metabolic syndrome and this causes insulin resistance leading to diabetes mellitus. Some anti-diabetic medications causes weight gain mostly through effect on metabolism. Correction of catabolic state of diabetes causing retention of calories, endogenous or exogenous insulin causing inhibition of lipolysis, reduction in leptin production and appetite stimulation from hypoglycaemic episodes contributes towards weight gain (Davtyan and Ma 2008). One of the side effects of thiazolidinediones is fluid retention (Davtyan and Ma 2008). Medications helping in weight loss is glucagon-like peptite-1 (GLP-1) (Nathan, Buse et al. 2009) while dipeptidyl-peptidase (DPP)-4 inhibitor (Dicker 2011), gliclazide modified release (Zoungas, Chalmers et al. 2010) and metformin(Nathan, Buse et al. 2009) are weight neutral . These might be better choice for obese patients if there are no contraindications. It is important to recognise drug induced weight gain and sometimes changing medications could enhance potential weight lost post surgery.

\section{Psychological assessment}

All patients who undergo surgery will need long term behavioural and eating habit changes. Indeed, some view bariatric surgery as a forced behavior modification (van Hout and van Heck 2009). Psychological and psychiatric disorders could lead to a negative outcome post operatively (Pull 2010). These include those who have active psychosis, current illicit drug users or alcohol abuse and personality disorders(Susan F. Franks 2008). Surgery is contraindicated in patients who are currently abusing drugs or alcohol (Susan F. Franks 2008; Snyder 2009). Patients with previous history of sexual abuse, found in a significant percentage of bariatric patients, will need more support as they might find difficulties with attention gained post surgery due to change in body image and thus risk regaining weight(Snyder 2009). Psychological disorders can include depression, anxiety, eating disorders and low self esteem (Abiles, Rodriguez-Ruiz et al. 2010). Patients known or suspected to have psychological or psychiatric disorders should be referred for further mental health assessment (Susan F. Franks 2008; Mechanick, Kushner et al. 2009) by a psychologist or psychiatrist. The assessment usually contains one or two parts: a clinical interview and psychological testing (Mechanick, Kushner et al. 2009; Snyder 2009). 


\subsection{Depression and anxiety}

Depression is very common (Susan F. Franks 2008; Snyder 2009; Abiles, Rodriguez-Ruiz et al. 2010) and prevalence is highly variable depending on the use of a choice of structured clinical interview for diagnostic and statistical manual of mental disorders (SCID) or clinical based diagnosis (Susan F. Franks 2008). Mild depressive disorder is relatively benign and might improve post surgery (Snyder 2009). On the other hand, severe depression with or without suicidal ideation could have adverse effects towards patients as they might have difficulty adhering with dietary or other advice provided(Snyder 2009). Patients will need these addressed prior to surgery (Mechanick, Kushner et al. 2009).

Anxiety is present in 15 to $37.5 \%$ of patients (Susan F. Franks 2008). Most patients' distress levels are reduced with weight loss post surgery (Ryden, Karlsson et al. 2003) but this could potentially cause problems with adaptability or ability to cope perioperatively (Snyder 2009).

\subsection{Eating disorder}

Eating disorder is common. This can include comfort eating from emotional stress or distress, binge eating, snacking (Mechanick, Kushner et al. 2009; Snyder 2009) and night time eating (Snyder 2009). Binge eating is characterised by subjective loss of control and consumed a large quantity of food within a short period (Snyder 2009). About $10-25 \%$ of patients have problems with binge eating (Snyder 2009). Psychologists could help alleviate the symptoms and reinforce the behaviour modification needed (Snyder 2009).

Night eating syndrome (NES) is characterised with night time hyperphagia, which is intake of $25 \%$ of total daily calories after evening meal, awaking from sleep to eat at night (Allison, Wadden et al. 2006; Howell, Schenck et al. 2009; Stunkard, Allison et al. 2009) and morning anorexia (Gluck, Geliebter et al. 2001). It is more common in women, and is associated with higher rate of depression, lower self-esteem and less day time hunger with poorer outcome in weight loss (Gluck, Geliebter et al. 2001). Patients with this condition should be considered for a referral to a psychologist for further evaluation and treatment. Sertraline has been shown to be useful in patients with night eating syndrome (O'Reardon, Allison et al. 2006).

Psychological assessments will help to distinguish patient who are contraindicated for surgery, improve patient's emotional well being and motivation as well as enhances patient's ability to cope with bariatric surgery (Snyder 2009).

\section{Dietary and nutrition assessment}

Food can be measured based on amount of calories. Weight is maintained when intake of calories equals expenditure. Obesity occurs when there is a chronic surplus of intake. Therefore, nutritional assessment by a specialist dietitian or nutritionist is essential. Assessment should again be holistic and this includes patient's lifestyle, eating habits, positive and negative influences on behaviour (Detitians in obesity management 2007). Practitioners should have specialist skills in nutritional assessment. Time recommended to evaluate lifestyle habits is initially is between 45 minutes and an hour with follow up appointments between 20 to 30 minutes (Detitians in obesity management 2007). 
The patient's weight history could help identify onset of weight problem either since childhood indicating a genetic contribution (Farooqi and O'Rahilly 2007) or any important life events causing initiation of weight problem such as pregnancy (Smith, Lewis et al. 1994). Assessment should also include previous efforts and outcomes of weight loss attempts. Gibbons et al showed that on average, individuals had 4.7 attempts in losing weight before seeking surgery (Gibbons, Sarwer et al. 2006). This enables positive factors to be identified and maintained and previous failures addressed (Detitians in obesity management 2007).

Bariatric surgery will help in weight loss but Swedish Obese Subjects (SOS) study has shown that after maximum weight loss at 1 year, patients start to regain some of the excess weight loss after 2 years and weight gain stabilized after 8 to 10 years (Sjostrom, Narbro et al. 2007). Lifestyle modifications which include changes in diet, physical activity and behavioural therapy are paramount in preventing this problem post surgery and assist in weight maintenance (National Heart, Blood et al. 1998; Wadden, Butryn et al. 2007; Tsigos, Hainer et al. 2008).

Apart from these, it is also important to look at cultural, religious and personal beliefs or preferences in different type of food and eating behaviour. The use of a food diary is an important tool to assess quantity and type of food intake as well as able to provide practical suggestions on changes (Detitians in obesity management 2007; Scottish Intercollegiate Guidelines and Scotland 2010). However, obese patients tend to under-report their dietary intake (Detitians in obesity management 2007; Scottish Intercollegiate Guidelines and Scotland 2010).

\subsection{Eating habits}

There are different dietary behaviours within the obese population. Some patients eat for comfort especially during stress or negative emotions (Elfhag and Rossner 2005). There are many different eating habits and detailed assessment of dietary intake is vital in providing specific action plans for different patients. Binge eating and night eating syndrome are eating disorders as described above (Allison, Wadden et al. 2006; Tsigos, Hainer et al. 2008). It is important to identify patients who have this problem and referred to psychologist for further treatment prior to proceeding for bariatric surgery (Detitians in obesity management 2007).

Skipping meals especially breakfast is a common habit (Ruxton and Kirk 1997; Wyatt, Grunwald et al. 2002). Breakfast especially with cereal is low in fat, high in carbohydrate, fibre and micronutrients (Ruxton and Kirk 1997). Researchers have shown breakfast consumption is associated with lower body weight (Ruxton and Kirk 1997) and better success with future maintenance of weight loss (Wyatt, Grunwald et al. 2002; Elfhag and Rossner 2005; Wing and Phelan 2005; Grief and Miranda 2010). Nevertheless, it is common for patients to not feel hungry in the morning after bariatric surgery. Other erratic eating habits include periods of fasting, snacking or grazing food (Detitians in obesity management 2007). Sometimes the spouse or partner provides excessive feeding towards the patient causing excessive eating. It is important to address these behaviours and educate patients to have a balanced three meals per day to maintain good nutritional status prior to surgery (Tsigos, Hainer et al. 2008). 


\subsection{Dietary treatment}

There are various types of food in the shelves of supermarkets and consumers have many different choices. Most food packaging now carry nutritional information on their labels for consumers to read. Educating patients to choose their food can help increase further awareness of label reading. Furthermore, it is also a good opportunity to educate patient to have a more balanced diet consisting of more fruits and vegetables, and less fat, salt and sugar ((FDA) 2004; NHS Choices 2011).

Nutritional requirements are different for each person depending on gender, height, weight, amount of physical activity and age. Dietitians could help to calculate the daily requirement while patients need to be taught how to read food label and perform their own calorie counting for their recommended daily calorie intake.

There are many dietary interventions available. The Dietary Approaches to Stop Hypertension (DASH) for obese patient with hypertension gives priority to a diet high in grain products, fruits, vegetables, low in fat and non dairy food. It has proven to lower blood pressure (Appel, Moore et al. 1997; Svetkey, Simons-Morton et al. 1999; Miller, Erlinger et al. 2006) and cholesterol (Miller, Erlinger et al. 2006). Other interventions that has shown success in weight loss include carbohydrate restriction diet including commercial weight loss programme (Nordmann, Nordmann et al. 2006; Gardner, Kiazand et al. 2007), the low glycaemic index diet (Thomas, Elliott et al. 2007), Mediterranean diet (Shai, Schwarzfuchs et al. 2008) and low fat diet(Nordmann, Nordmann et al. 2006).

\subsection{Six hundred calorie deficit diet}

It is recommended for patient to aim to lose weight of no more than $0.5-1 \mathrm{~kg}(1-2 \mathrm{Ib})$ per week (Heart, Blood et al. 1997; 2006; Scottish Intercollegiate Guidelines and Scotland 2010) and this equivalent to a calorie deficit of 500 to $1000 \mathrm{kcal}$ per day for 6 months (National Heart, Blood et al. 1998; Scottish Intercollegiate Guidelines and Scotland 2010); hence the 600kcal deficit approach (Detitians in obesity management 2007; Tsigos, Hainer et al. 2008; Scottish Intercollegiate Guidelines and Scotland 2010). Dietician will calculate the patient's estimated energy requirement and subtract it by $600 \mathrm{kcal}$ per day resulting in a negative balance (Detitians in obesity management 2007). This could be individualised to each patients' needs and preferences in food but should still maintain a healthy and balanced diet.

\subsubsection{Low energy and very low energy diets}

Patients who need to achieve a more rapid weight loss could try the more restricted calorie diet (Detitians in obesity management 2007; Tsigos, Hainer et al. 2008; Scottish Intercollegiate Guidelines and Scotland 2010). Low energy diet consists of total daily calories of between 800 to $1,500 \mathrm{kcal}$ and very low energy diet consists of less than $800 \mathrm{kcal}$ per day (National Heart, Blood et al. 1998; Detitians in obesity management 2007; Tsigos, Hainer et al. 2008; Scottish Intercollegiate Guidelines and Scotland 2010) or $<50 \%$ reduction of the patient's predicted resting energy expenditure (Tsai and Wadden 2006). Low energy diet is associated with 5-8\% of weight loss (National Heart, Blood et al. 1998; Scottish Intercollegiate Guidelines and Scotland 2010) over 12 months and this could be 
individualised to the patient's food preference (National Heart, Blood et al. 1998). Micronutrient supplementations are occasional necessary.

Very low energy diet (VLED) is usually a liquid diet consisting of a large amount of protein, up to $80 \mathrm{~g}$ of carbohydrate and $15 \mathrm{~g}$ of fat per day and fortified with micronutrients (Tsai and Wadden 2006). This intervention need to be done under close medical supervision (1993; Detitians in obesity management 2007; Tsigos, Hainer et al. 2008; Scottish Intercollegiate Guidelines and Scotland 2010). Maximum recommended duration of this intervention is 12 weeks (Detitians in obesity management 2007). The patient needs to consume a minimum of 2 litre of non-caloric fluid per day while on this diet (Tsai and Wadden 2006). Cambridge Weight Plan previously known as the Cambridge Diet uses VLED intervention. Adverse effects during this treatment include cholelithiasis, cold intolerance, hair loss, headache, fatigue, dizziness, muscle cramps, constipation, volume depletion and rarely cardiac complications causing death if unsupervised (1993; Tsai and Wadden 2006). Total weight loss at 12 months for VLED is similar to low calorie diet (National Heart, Blood et al. 1998; Tsai and Wadden 2006; Scottish Intercollegiate Guidelines and Scotland 2010). During first 3 to 4 months, initial weight loss with VLED is about $25-50 \%$ but patient regained $40-50 \%$ of the weight lost within 1-2 years while on VLED (Tsai and Wadden 2006) hence it is suitable for rapid weight loss. One study showed remission of type 2 diabetes in obese patient after 8 weeks of VLED (Lim, Hollingsworth et al. 2011).

VLED with liquid diet or low energy diet substituted with one or two of the three daily main meals and this intervention is called meal replacement intervention (Tsigos, Hainer et al. 2008). As the liquid diet consists of necessary micronutrients, this may help in weight loss while maintaining a balanced nutrition (Tsigos, Hainer et al. 2008); the low energy diet replacement needed to be fortified with the necessary vitamins and minerals (Heymsfield, van Mierlo et al. 2003). It is shown that meal replacement intervention induce between 6.97 to $7.31 \mathrm{~kg}$ of weight loss at 1 year follow up as compared to $2.61-4.35 \mathrm{~kg}$ with low energy diet alone (Heymsfield, van Mierlo et al. 2003).

\section{Lifestyle intervention}

After dietary changes in reducing calorie intake, the next step would be to increase in physical activity and finally help in engaging the patient for a more permanent change in lifestyle. Physical activity for about 30-60 min per day for at least 5 days a week of moderate intensity such as brisk walking has been recommended by various guidelines (National Heart, Blood et al. 1997; 2006; Tsigos, Hainer et al. 2008; Scottish Intercollegiate Guidelines and Scotland 2010). Increased physical activity has added effect on weight loss compared to just dietary interventions alone (Jakicic 2009; Goodpaster, Delany et al. 2010). It also improves cardiorespiratory fitness (National Heart, Blood et al. 1998), reduces cardiovascular risks (National Heart, Blood et al. 1998; Tsigos, Hainer et al. 2008; Goodpaster, Delany et al. 2010; Vetter, Faulconbridge et al. 2010), reduces abdominal fat (Jones, Wilson et al. 2007), improves anxiety and depression and helps with long term weight management(Jones, Wilson et al. 2007; Tsigos, Hainer et al. 2008; Jakicic 2009). Patients should also be encouraged to avoid sedentary lifestyle by choosing to use the stairs rather than elevators, walking or cycling to nearby places rather than driving and doing gardening (Vetter, Faulconbridge et al. 2010). 
It has been shown by the Diabetes Prevention Programme (Knowler, Barrett-Connor et al. 2002) and the Finnish Diabetes Prevention studies (Tuomilehto, Lindstrom et al. 2001) that intensive lifestyle interventions promote weight loss of between $3.5-5.6 \mathrm{~kg}$. The Look AHEAD trial reported $6.15 \%$ weight loss after 4 years of interventions (Wing 2010). Most of the academic centres provide initial weekly interventions for a period of 16 to 26 weeks (Wadden, Butryn et al. 2007; Vetter, Faulconbridge et al. 2010). The entire treatment programme should be well structured along the lines of the Diabetes Prevention Programme. It is also more cost effective to have group sessions. Moreover, group sessions provide additional benefits on greater initial weight loss, better social support and healthy competition between members (Wadden, Butryn et al. 2007; Vetter, Faulconbridge et al. 2010).

Even after successful initial weight loss, weight regain could occur prior to surgery. Reasons behind weight regain are likely to be multifactorial including behavioural fatigue (Tsai and Wadden 2006), leaving from highly supportive care and return to initial 'damaging' environment or influence (Vetter, Faulconbridge et al. 2010). Hence health care professionals and patients should aim for long term behavioural change and it is the key in preventing weight regain prior and post surgery.

\section{Final steps prior to surgery}

After medical, psychological and nutritional assessments, the team will need to meet together to provide insight of the patients' conditions and discuss suitability of surgical interventions in them. Some centres propose a minimum $5-10 \%$ weight loss prior to surgery as some studies have shown this decreases length of hospital stay (Still, Benotti et al. 2007), reduces operative time (Huerta, Dredar et al. 2008) and less complications (Liu, Sabnis et al. 2005). As most of the dietary advice post surgery advises patients to have a liquid diet first, it is also important to review all patients' medications pre-surgery and change medications into liquid or soluble form prior to surgery.

\section{Conclusion}

Assessing and preparing patients for bariatric surgery is a complex process requiring input from a multi-disciplinary team. The primary aim is to optimise treatment of patients' preexisting conditions hence minimising peri and post-operative complications and mortality. The surgery itself is only the first step. Post operatively, bariatric team members as well as patients' general practitioners need to continue to encourage patients' adherence to lifestyle changes including dietary energy restriction and increase in physical activity to help in longterm weight maintenance.

\section{Acknowledgement}

The views expressed in this publication are not necessarily those of the NIHR, the Department of Health, NHS South Birmingham, University of Birmingham or the CLAHRC-BBC Theme 8 Management/Steering group.

This work was funded by the National Institute for Health Research (NIHR) through the Collaborations for Leadership in Applied Health Research and Care for Birmingham and Black Country (CLAHRC-BBC) programme 


\section{References}

"Cambridge weight plan." from http:/ / www.cambridgeweightplan.com/

"The DASH diet eating plan." from http:// dashdiet.org/ default.asp.

(1993). "Very low-calorie diets. National Task Force on the Prevention and Treatment of Obesity, National Institutes of Health." JAMA 270(8): 967-974.

(2002). "Third Report of the National Cholesterol Education Program (NCEP) Expert Panel on Detection, Evaluation, and Treatment of High Blood Cholesterol in Adults (Adult Treatment Panel III) final report." Circulation 106(25): 3143-3421.

(2006). Obesity [electronic resource]: the prevention, identification, assessment and management of overweight and obesity in adults and children : NICE clinical guidance 43. [London], NICE.

(2008). Worried about gaining weight when you stop smoking? . Scottish nutrition and diet resources initiative (SNDRi). UK, Scottish Government. 1005 05/05.

(2009). Management of type 2 diabetes: NICE guidelines, Royal College of Physicians.

2010). You can control your weight as you quit smoking. U.S. Department of Health and Human Services. N. I. o. D. a. D. a. K. Diseases. United States, National Institute of Health. 03-4159: 1-7.

(2010). "European Medicines Agency recommends suspension of Avandia, Avandamet and Avaglim." from

http:/ / www.ema.europa.eu/ema/index.jsp?curl=pages/news_and_events/news /2010/09/news_detail_001119.jsp\&mid=WC0b01ac058004d5c1\&murl=menus/ne ws_and_events/news_and_events.jsp\&jsenabled=true.

(2010). "Rosiglitazone: recommended withdrawal from clinical use." from http://www.mhra.gov.uk/Safetyinformation/Safetywarningsalertsandrecalls/Saf etywarningsandmessagesformedicines/CON094121

(2010). "U S. Medical Eligibility Criteria for Contraceptive Use, 2010." MMWR Recomm Rep 59(RR-4): 1-86.

(2011). "Executive summary: standards of medical care in diabetes--2011." Diabetes Care 34 Suppl 1: S4-10.

(2011). "Updated risk evaluation and mitigation strategy (REMS) to restrict access to rosiglitazone-containing medicines including Avandia, Avandamet and Avandaryl." from http://www.fda.gov/Drugs/DrugSafety/ucm255005.htm

NICE CG 67, (2010, March 2010). "Lipid Modification: cardiovascular risk assessment and the modification of blood lipids for the primary and secondary prevention of cardiovascular disease." Retrieved 20/08/2011, from http://www.nice.org.uk/nicemedia/live/11982/40689/40689.pdf

FDA, (2004, November 2004). "How to understand and use the nutrition facts label." Retrieved 26/8/2011, from

http://www.fda.gov/food/labelingnutrition/consumerinformation/ucm078889.h tm.

(WIN), W. C. N. (2010). You can control your weight as you quit smoking. N. I. o. D. a. D. a. K. Diseases. United States, National Institute of Health. 03-4159: 1-7.

Abiles, V., S. Rodriguez-Ruiz, et al. (2010). "Psychological characteristics of morbidly obese candidates for bariatric surgery." Obes Surg 20(2): 161-167.

Alberti, K. G., P. Zimmet, et al. (2005). "The metabolic syndrome--a new worldwide definition." Lancet 366(9491): 1059-1062. 
Allison, K. C., T. A. Wadden, et al. (2006). "Night eating syndrome and binge eating disorder among persons seeking bariatric surgery: prevalence and related features." Obesity (Silver Spring) 14 Suppl 2: 77S-82S.

Alpert, M. A., B. E. Terry, et al. (2000). "The electrocardiogram in morbid obesity." Am J Cardiol 85(7): 908-910, A910.

Appel, L. J., T. J. Moore, et al. (1997). "A clinical trial of the effects of dietary patterns on blood pressure. DASH Collaborative Research Group." N Engl J Med 336(16): 1117-1124.

Arslan, E., O. Yiginer, et al. (2010). "Effect of uncomplicated obesity on QT interval in young men." Pol Arch Med Wewn 120(6): 209-213.

Athyros, V. G., K. Tziomalos, et al. (2011). "Dyslipidaemia of obesity, metabolic syndrome and type 2 diabetes mellitus: the case for residual risk reduction after statin treatment." Open Cardiovasc Med J 5: 24-34.

Atmaca, M., M. Kuloglu, et al. (2002). "Weight gain and serum leptin levels in patients on lithium treatment." Neuropsychobiology 46(2): 67-69.

Avelar, E., T. V. Cloward, et al. (2007). "Left ventricular hypertrophy in severe obesity: interactions among blood pressure, nocturnal hypoxemia, and body mass." Hypertension 49(1): 34-39.

Avenell, A., J. Broom, et al. (2004). "Systematic review of the long-term effects and economic consequences of treatments for obesity and implications for health improvement." Health Technol Assess 8(21): iii-iv, 1-182.

Balen, A. (2007). Polycystic ovarian syndrome, obesity and reproductive function. London, RCOG press.

Barr, J. and J. Cunneen (2001). "Understanding the bariatric client and providing a safe hospital environment." Clin Nurse Spec 15(5): 219-223.

Benjamin, E. J. and D. Levy (1999). "Why is left ventricular hypertrophy so predictive of morbidity and mortality?" Am J Med Sci 317(3): 168-175.

Brown, C. D., M. Higgins, et al. (2000). "Body mass index and the prevalence of hypertension and dyslipidemia." Obes Res 8(9): 605-619.

Buchwald, H., R. Estok, et al. (2009). "Weight and type 2 diabetes after bariatric surgery: systematic review and meta-analysis." Am J Med 122(3): 248-256 e245.

Caruana, J. A., M. N. McCabe, et al. (2005). "Incidence of symptomatic gallstones after gastric bypass: is prophylactic treatment really necessary?" Surg Obes Relat Dis 1(6): 564-567; discussion 567-568.

Casey, K. R., K. O. Cantillo, et al. (2007). "Sleep-related hypoventilation/hypoxemic syndromes." Chest 131(6): 1936-1948.

Chan, J. M., E. B. Rimm, et al. (1994). "Obesity, fat distribution, and weight gain as risk factors for clinical diabetes in men." Diabetes Care 17(9): 961-969.

Chiolero, A., D. Faeh, et al. (2008). "Consequences of smoking for body weight, body fat distribution, and insulin resistance." Am J Clin Nutr 87(4): 801-809.

Chobanian, A. V., G. L. Bakris, et al. (2003). "Seventh report of the Joint National Committee on Prevention, Detection, Evaluation, and Treatment of High Blood Pressure." Hypertension 42(6): 1206-1252.

Choices, N. (2011, 21/3/2011). "Food labels." Retrieved 26/8/2011, from http://www.nhs.uk/Livewell/Goodfood/Pages/food-labelling.aspx.

Clain, D. J. and J. H. Lefkowitch (1987). "Fatty liver disease in morbid obesity." Gastroenterol Clin North Am 16(2): 239-252.

Collop, N. A., W. M. Anderson, et al. (2007). "Clinical guidelines for the use of unattended portable monitors in the diagnosis of obstructive sleep apnea in adult patients. 
Portable Monitoring Task Force of the American Academy of Sleep Medicine." J Clin Sleep Med 3(7): 737-747.

Corley, D. A. and A. Kubo (2006). "Body mass index and gastroesophageal reflux disease: a systematic review and meta-analysis." Am J Gastroenterol 101(11): 2619-2628.

Davtyan, C. and M. Ma (2008) "Drug-induced weight gain." Proceedings of UCLA Healthcare 12, 1-9.

de la Maza, M. P., A. Estevez, et al. (1994). "Ventricular mass in hypertensive and normotensive obese subjects." Int J Obes Relat Metab Disord 18(4): 193-197.

De Ridder, R. J., E. J. Schoon, et al. (2007). "Review article: Non-alcoholic fatty liver disease in morbidly obese patients and the effect of bariatric surgery." Aliment Pharmacol Ther 26 Suppl 2: 195-201.

Delgado-Aros, S., G. R. Locke, 3rd, et al. (2004). "Obesity is associated with increased risk of gastrointestinal symptoms: a population-based study." Am J Gastroenterol 99(9): 1801-1806.

Detitians in obesity management (2007). The dietetic weight management intervention for adults in the one to one setting. Is it time for radical rethink? , DOM UK.

Diaz, M. E. (2002). "Hypertension and obesity." J Hum Hypertens 16 Suppl 1: S18-22.

Dicker, D. (2011). "DPP-4 inhibitors: impact on glycemic control and cardiovascular risk factors." Diabetes Care 34 Suppl 2: S276-278.

Dixon, J. B., M. E. Dixon, et al. (2001). "Pre-operative predictors of weight loss at 1-year after Lap-Band surgery." Obes Surg 11(2): 200-207.

Eichinger, S., G. Hron, et al. (2008). "Overweight, obesity, and the risk of recurrent venous thromboembolism." Arch Intern Med 168(15): 1678-1683.

Eisenstein, I., J. Edelstein, et al. (1982). "The electrocardiogram in obesity." J Electrocardiol 15(2): 115-118.

El-Serag, H. B., D. Y. Graham, et al. (2005). "Obesity is an independent risk factor for GERD symptoms and erosive esophagitis." Am J Gastroenterol 100(6): 1243-1250.

Elfhag, K. and S. Rossner (2005). "Who succeeds in maintaining weight loss? A conceptual review of factors associated with weight loss maintenance and weight regain." Obes Rev 6(1): 67-85.

Epstein, L. J., D. Kristo, et al. (2009). "Clinical guideline for the evaluation, management and long-term care of obstructive sleep apnea in adults." J Clin Sleep Med 5(3): 263-276.

Farooqi, I. S. and S. O'Rahilly (2007). "Genetic factors in human obesity." Obes Rev 8 Suppl 1: $37-40$.

Farquhar, C. (2007). Obesity and fertility. London, RCOG press.

Flegal, K. M., R. P. Troiano, et al. (1995). "The influence of smoking cessation on the prevalence of overweight in the United States." N Engl J Med 333(18): 1165-1170.

Flum, D. R., S. H. Belle, et al. (2009). "Perioperative safety in the longitudinal assessment of bariatric surgery." N Engl J Med 361(5): 445-454.

Foster, G. D., T. A. Wadden, et al. (2001). "Obese patients' perceptions of treatment outcomes and the factors that influence them." Arch Intern Med 161(17): 2133-2139.

Fox, C. S., S. Coady, et al. (2007). "Increasing cardiovascular disease burden due to diabetes mellitus: the Framingham Heart Study." Circulation 115(12): 1544-1550.

Frank, S., J. A. Colliver, et al. (1986). "The electrocardiogram in obesity: statistical analysis of 1,029 patients." J Am Coll Cardiol 7(2): 295-299.

Gardner, C. D., A. Kiazand, et al. (2007). "Comparison of the Atkins, Zone, Ornish, and LEARN diets for change in weight and related risk factors among overweight premenopausal women: the A TO Z Weight Loss Study: a randomized trial." JAMA 297(9): 969-977. 
Gibbons, L. M., D. B. Sarwer, et al. (2006). "Previous weight loss experiences of bariatric surgery candidates: how much have patients dieted prior to surgery?" Obesity (Silver Spring) 14 Suppl 2: 70S-76S.

Gibson, G. J. (2000). "Obesity, respiratory function and breathlessness." Thorax 55 Suppl 1: S41-44.

Ginsberg, H. N. and P. R. Maccallum (2009). "The obesity, metabolic syndrome, and type 2 diabetes mellitus pandemic: II. Therapeutic management of atherogenic dyslipidemia." J Clin Hypertens (Greenwich) 11(9): 520-527.

Gluck, M. E., A. Geliebter, et al. (2001). "Night eating syndrome is associated with depression, low self-esteem, reduced daytime hunger, and less weight loss in obese outpatients." Obes Res 9(4): 264-267.

Goodpaster, B. H., J. P. Delany, et al. (2010). "Effects of diet and physical activity interventions on weight loss and cardiometabolic risk factors in severely obese adults: a randomized trial." JAMA 304(16): 1795-1802.

Greenman, Y., K. Tordjman, et al. (1998). "Increased body weight associated with prolactin secreting pituitary adenomas: weight loss with normalization of prolactin levels." Clin Endocrinol (Oxf) 48(5): 547-553.

Grief, S. N. and R. L. Miranda (2010). "Weight loss maintenance." Am Fam Physician 82(6): 630-634.

Guelinckx, I., R. Devlieger, et al. (2009). "Reproductive outcome after bariatric surgery: a critical review." Hum Reprod Update 15(2): 189-201.

Hammoud, A., M. Gibson, et al. (2009). "Effect of Roux-en-Y gastric bypass surgery on the sex steroids and quality of life in obese men." J Clin Endocrinol Metab 94(4): 1329-1332.

Heinberg, L. J., K. Keating, et al. (2010). "Discrepancy between ideal and realistic goal weights in three bariatric procedures: who is likely to be unrealistic?" Obes Surg 20(2): 148-153.

Heymsfield, S. B., C. A. van Mierlo, et al. (2003). "Weight management using a meal replacement strategy: meta and pooling analysis from six studies." Int J Obes Relat Metab Disord 27(5): 537-549.

Hezelgrave, N. L. and E. Oteng-Ntim (2011). "Pregnancy after bariatric surgery: a review." J Obes 2011: 501939.

Howell, M. J., C. H. Schenck, et al. (2009). "A review of nighttime eating disorders." Sleep Med Rev 13(1): 23-34.

Hubert, H. B., M. Feinleib, et al. (1983). "Obesity as an independent risk factor for cardiovascular disease: a 26-year follow-up of participants in the Framingham Heart Study." Circulation 67(5): 968-977.

Huerta, S., S. Dredar, et al. (2008). "Preoperative weight loss decreases the operative time of gastric bypass at a Veterans Administration hospital." Obes Surg 18(5): 508-512.

Jakicic, J. M. (2009). "The effect of physical activity on body weight." Obesity (Silver Spring) 17 Suppl 3: S34-38.

Johns, M. W. (1991). "A new method for measuring daytime sleepiness: the Epworth sleepiness scale." Sleep 14(6): 540-545.

Jones, L. R., C. I. Wilson, et al. (2007). "Lifestyle modification in the treatment of obesity: an educational challenge and opportunity." Clin Pharmacol Ther 81(5): 776-779.

Jones, R. L. and M. M. Nzekwu (2006). "The effects of body mass index on lung volumes." Chest 130(3): 827-833.

Jones, S., V. Srinivasan, et al. (2007). Treating menstrual disturbance including pelvic pain (excluding PCOS). London, RCOG press. 
Jonsson, S., B. Hedblad, et al. (2002). "Influence of obesity on cardiovascular risk. Twentythree-year follow-up of 22,025 men from an urban Swedish population." Int J Obes Relat Metab Disord 26(8): 1046-1053.

Kaila, B. and M. Raman (2008). "Obesity: a review of pathogenesis and management strategies." Can J Gastroenterol 22(1): 61-68.

Kannel, W. B. (1996). "Blood pressure as a cardiovascular risk factor: prevention and treatment." JAMA 275(20): 1571-1576.

Knowler, W. C., E. Barrett-Connor, et al. (2002). "Reduction in the incidence of type 2 diabetes with lifestyle intervention or metformin." N Engl J Med 346(6): 393-403.

Knudsen, N., P. Laurberg, et al. (2005). "Small differences in thyroid function may be important for body mass index and the occurrence of obesity in the population." J Clin Endocrinol Metab 90(7): 4019-4024.

Koh-Banerjee, P., Y. Wang, et al. (2004). "Changes in body weight and body fat distribution as risk factors for clinical diabetes in US men." Am J Epidemiol 159(12): 1150-1159.

Kok, P., F. Roelfsema, et al. (2004). "Prolactin release is enhanced in proportion to excess visceral fat in obese women." J Clin Endocrinol Metab 89(9): 4445-4449.

Kok, P., F. Roelfsema, et al. (2006). "Increased circadian prolactin release is blunted after body weight loss in obese premenopausal women." Am J Physiol Endocrinol Metab 290(2): E218-224.

Kopelman, P. G. (2000). "Physiopathology of prolactin secretion in obesity." Int J Obes Relat Metab Disord 24 Suppl 2: S104-108.

Kuchenbecker, W. K., H. Groen, et al. (2010). "The subcutaneous abdominal fat and not the intraabdominal fat compartment is associated with anovulation in women with obesity and infertility." J Clin Endocrinol Metab 95(5): 2107-2112.

Kulie, T., A. Slattengren, et al. (2011). "Obesity and women's health: an evidence-based review." J Am Board Fam Med 24(1): 75-85.

Kulkarni, S. K. and G. Kaur (2001). "Pharmacodynamics of drug-induced weight gain." Drugs Today (Barc) 37(8): 559-571.

Lagergren, J., R. Bergstrom, et al. (1999). "Symptomatic gastroesophageal reflux as a risk factor for esophageal adenocarcinoma." N Engl J Med 340(11): 825-831.

Lauer, M. S., K. M. Anderson, et al. (1991). "The impact of obesity on left ventricular mass and geometry. The Framingham Heart Study." JAMA 266(2): 231-236.

Lavie, C. J., R. V. Milani, et al. (2009). "Obesity and cardiovascular disease: risk factor, paradox, and impact of weight loss." J Am Coll Cardiol 53(21): 1925-1932.

Leslie, W. S., C. R. Hankey, et al. (2007). "Weight gain as an adverse effect of some commonly prescribed drugs: a systematic review." QJM 100(7): 395-404.

Liew, P. L., W. J. Lee, et al. (2006). "Hepatic histopathology of morbid obesity: concurrence of other forms of chronic liver disease." Obes Surg 16(12): 1584-1593.

Lim, E. L., K. G. Hollingsworth, et al. (2011). "Reversal of type 2 diabetes: normalisation of beta cell function in association with decreased pancreas and liver triacylglycerol." Diabetologia.

Liu, R. C., A. A. Sabnis, et al. (2005). "The effects of acute preoperative weight loss on laparoscopic Roux-en-Y gastric bypass." Obes Surg 15(10): 1396-1402.

Locke, G. R., 3rd, N. J. Talley, et al. (1997). "Prevalence and clinical spectrum of gastroesophageal reflux: a population-based study in Olmsted County, Minnesota." Gastroenterology 112(5): 1448-1456.

Lopez-Jimenez, F. and M. Cortes-Bergoderi (2011). "Update: systemic diseases and the cardiovascular system (i): obesity and the heart." Rev Esp Cardiol 64(2): 140-149. 
Lupsor, M., R. Badea, et al. (2010). "Performance of unidimensional transient elastography in staging non-alcoholic steatohepatitis." J Gastrointestin Liver Dis 19(1): 53-60.

MacDonald, A. A., G. P. Herbison, et al. (2010). "The impact of body mass index on semen parameters and reproductive hormones in human males: a systematic review with meta-analysis." Hum Reprod Update 16(3): 293-311.

Maenhaut, N. and J. Van de Voorde (2011). "Regulation of vascular tone by adipocytes." BMC Med 9: 25.

Makimattila, S., K. Nikkila, et al. (1999). "Causes of weight gain during insulin therapy with and without metformin in patients with Type II diabetes mellitus." Diabetologia 42(4): 406-412.

McClean, K. M., F. Kee, et al. (2008). "Obesity and the lung: 1. Epidemiology." Thorax 63(7): 649-654.

McGill, H. C., Jr., C. A. McMahan, et al. (2002). "Obesity accelerates the progression of coronary atherosclerosis in young men." Circulation 105(23): 2712-2718.

Mechanick, J. I., R. F. Kushner, et al. (2009). "American Association of Clinical Endocrinologists, The Obesity Society, and American Society for Metabolic \& Bariatric Surgery medical guidelines for clinical practice for the perioperative nutritional, metabolic, and nonsurgical support of the bariatric surgery patient." Obesity (Silver Spring) 17 Suppl 1: S1-70, v.

Miller, E. R., 3rd, T. P. Erlinger, et al. (2006). "The effects of macronutrients on blood pressure and lipids: an overview of the DASH and OmniHeart trials." Curr Atheroscler Rep 8(6): 460-465.

Mokhlesi, B. (2010). "Obesity hypoventilation syndrome: a state-of-the-art review." Respir Care 55(10): 1347-1362; discussion 1363-1345.

Mokhlesi, B., M. H. Kryger, et al. (2008). "Assessment and management of patients with obesity hypoventilation syndrome." Proc Am Thorac Soc 5(2): 218-225.

Mokhlesi, B. and A. Tulaimat (2007). "Recent advances in obesity hypoventilation syndrome." Chest 132(4): 1322-1336.

Movahed, M. R., A. Martinez, et al. (2009). "Left ventricular hypertrophy is associated with obesity, male gender, and symptoms in healthy adolescents." Obesity (Silver Spring) 17(3): 606-610.

Myers, R. P., G. Pomier-Layrargues, et al. (2011). "Feasibility and diagnostic performance of the fibroscan $\mathrm{xl}$ probe for liver stiffness measurement in overweight and obese patients." Hepatology.

Narkiewicz, K. (2006). "Obesity and hypertension--the issue is more complex than we thought." Nephrol Dial Transplant 21(2): 264-267.

Nathan, D. M., J. B. Buse, et al. (2009). "Medical management of hyperglycaemia in type 2 diabetes mellitus: a consensus algorithm for the initiation and adjustment of therapy: a consensus statement from the American Diabetes Association and the European Association for the Study of Diabetes." Diabetologia 52(1): 17-30.

National Heart, L., I. Blood, et al. (1998). Clinical guidelines on the identification, evaluation, and treatment of overweight and obesity in adults [electronic resource]: the evidence report. [Bethesda, Md.?], National Heart, Lung.

Ness-Abramof, R. and C. M. Apovian (2005). "Drug-induced weight gain." Drugs Today (Barc) 41(8): 547-555.

Netzer, N. C., R. A. Stoohs, et al. (1999). "Using the Berlin Questionnaire to identify patients at risk for the sleep apnea syndrome." Ann Intern Med 131(7): 485-491.

Nguyen, R. H., A. J. Wilcox, et al. (2007). "Men's body mass index and infertility." Hum Reprod 22(9): 2488-2493. 
Nieman, L. K., B. M. Biller, et al. (2008). "The diagnosis of Cushing's syndrome: an Endocrine Society Clinical Practice Guideline." J Clin Endocrinol Metab 93(5): 1526-1540.

Nihalani, N., T. L. Schwartz, et al. (2011). "Weight gain, obesity, and psychotropic prescribing." J Obes 2011: 893629.

Nordmann, A. J., A. Nordmann, et al. (2006). "Effects of low-carbohydrate vs low-fat diets on weight loss and cardiovascular risk factors: a meta-analysis of randomized controlled trials." Arch Intern Med 166(3): 285-293.

Nyrnes, A., R. Jorde, et al. (2006). "Serum TSH is positively associated with BMI." Int J Obes (Lond) 30(1): 100-105.

O'Reardon, J. P., K. C. Allison, et al. (2006). "A randomized, placebo-controlled trial of sertraline in the treatment of night eating syndrome." Am J Psychiatry 163(5): 893-898.

Orth, D. N. (1995). "Cushing's syndrome." N Engl J Med 332(12): 791-803.

Pasquali, R., L. Patton, et al. (2007). "Obesity and infertility." Curr Opin Endocrinol Diabetes Obes 14(6): 482-487.

Pasquali, R., C. Pelusi, et al. (2003). "Obesity and reproductive disorders in women." Hum Reprod Update 9(4): 359-372.

Paulen, M. E., L. B. Zapata, et al. (2010). "Contraceptive use among women with a history of bariatric surgery: a systematic review." Contraception 82(1): 86-94.

Peeters, A., J. J. Barendregt, et al. (2003). "Obesity in adulthood and its consequences for life expectancy: a life-table analysis." Ann Intern Med 138(1): 24-32.

Poirier, P., T. D. Giles, et al. (2006). "Obesity and cardiovascular disease: pathophysiology, evaluation, and effect of weight loss: an update of the 1997 American Heart Association Scientific Statement on Obesity and Heart Disease from the Obesity Committee of the Council on Nutrition, Physical Activity, and Metabolism." Circulation 113(6): 898-918.

Pontiroli, A. E., P. Pizzocri, et al. (2004). "Left ventricular hypertrophy and QT interval in obesity and in hypertension: effects of weight loss and of normalisation of blood pressure." Int J Obes Relat Metab Disord 28(9): 1118-1123.

Priou, P., J. F. Hamel, et al. (2010). "Long-term outcome of noninvasive positive pressure ventilation for obesity hypoventilation syndrome." Chest 138(1): 84-90.

Pull, C. B. (2010). "Current psychological assessment practices in obesity surgery programs: what to assess and why." Curr Opin Psychiatry 23(1): 30-36.

Qatanani, M. and M. A. Lazar (2007). "Mechanisms of obesity-associated insulin resistance: many choices on the menu." Genes Dev 21(12): 1443-1455.

Quesada, B. M., G. Kohan, et al. (2010). "Management of gallstones and gallbladder disease in patients undergoing gastric bypass." World J Gastroenterol 16(17): 2075-2079.

Rabec, C., P. de Lucas Ramos, et al. (2011). "Respiratory complications of obesity." Arch Bronconeumol 47(5): 252-261.

Reinehr, T. (2010). "Obesity and thyroid function." Mol Cell Endocrinol 316(2): 165-171.

Ruhl, C. E. and J. E. Everhart (2005). "Joint effects of body weight and alcohol on elevated serum alanine aminotransferase in the United States population." Clin Gastroenterol Hepatol 3(12): 1260-1268.

Ruxton, C. H. and T. R. Kirk (1997). "Breakfast: a review of associations with measures of dietary intake, physiology and biochemistry." Br J Nutr 78(2): 199-213.

Ryden, A., J. Karlsson, et al. (2003). "Coping and distress: what happens after intervention? A 2-year follow-up from the Swedish Obese Subjects (SOS) study." Psychosom Med 65(3): 435-442.

Salgado Junior, W., J. S. Santos, et al. (2006). "Nonalcoholic fatty liver disease and obesity." Acta Cir Bras 21 Suppl 1: 72-78. 
Scaglioni, F., S. Ciccia, et al. (2011). "ASH and NASH." Dig Dis 29(2): 202-210.

Scottish Intercollegiate Guidelines (2003). Management of obstructive sleep apnoea/hypopnoea syndrome in adults. Edinburgh, Scottish Intercollegiate Guidelines Network.

Scottish Intercollegiate Guidelines (2010). Management of obesity: a national clinical guideline. Edinburgh, Scottish Intercollegiate Guidelines Network.

Seyfeli, E., M. Duru, et al. (2006). "Effect of obesity on P-wave dispersion and QT dispersion in women." Int J Obes (Lond) 30(6): 957-961.

Shah, D. K. and E. S. Ginsburg (2010). "Bariatric surgery and fertility." Curr Opin Obstet Gynecol 22(3): 248-254.

Shai, I., D. Schwarzfuchs, et al. (2008). "Weight loss with a low-carbohydrate, Mediterranean, or low-fat diet." N Engl J Med 359(3): 229-241.

Sjostrom, L., A. K. Lindroos, et al. (2004). "Lifestyle, diabetes, and cardiovascular risk factors 10 years after bariatric surgery." N Engl J Med 351(26): 2683-2693.

Sjostrom, L., K. Narbro, et al. (2007). "Effects of bariatric surgery on mortality in Swedish obese subjects." N Engl J Med 357(8): 741-752.

Smith, D. E., C. E. Lewis, et al. (1994). "Longitudinal changes in adiposity associated with pregnancy. The CARDIA Study. Coronary Artery Risk Development in Young Adults Study." JAMA 271(22): 1747-1751.

Snyder, A. G. (2009). "Psychological assessment of the patient undergoing bariatric surgery." Ochsner J 9(3): 144-148.

Sood, A. (2009). "Altered resting and exercise respiratory physiology in obesity." Clin Chest Med 30(3): 445-454, vii.

Srivastava, S. and Z. M. Younossi (2005). "Morbid obesity, nonalcoholic fatty liver disease, and weight loss surgery." Hepatology 42(2): 490-492.

Stamler, R., J. Stamler, et al. (1978). "Weight and blood pressure. Findings in hypertension screening of 1 million Americans." JAMA 240(15): 1607-1610.

Stein, P. D., A. Beemath, et al. (2005). "Obesity as a risk factor in venous thromboembolism." Am J Med 118(9): 978-980.

Wilcox, I. (2010). Cardiovascular consequences of obesity. UK, Wiley-Blackwell.

Still, C. D., P. Benotti, et al. (2007). "Outcomes of preoperative weight loss in high-risk patients undergoing gastric bypass surgery." Arch Surg 142(10): 994-998; discussion 999.

Stunkard, A. J., K. C. Allison, et al. (2009). "Development of criteria for a diagnosis: lessons from the night eating syndrome." Compr Psychiatry 50(5): 391-399.

Susan F. Franks, a. K. A. K. (2008). "Predictive factors in bariatric surgery outcomes: what is the role of the preoperative psychological evaluation?" Primary psychiatry 15(8): 74-83.

Svetkey, L. P., D. Simons-Morton, et al. (1999). "Effects of dietary patterns on blood pressure: subgroup analysis of the Dietary Approaches to Stop Hypertension (DASH) randomized clinical trial." Arch Intern Med 159(3): 285-293.

Talley, N. J., S. Howell, et al. (2004). "Obesity and chronic gastrointestinal tract symptoms in young adults: a birth cohort study." Am J Gastroenterol 99(9): 1807-1814.

Thomas, D. E., E. J. Elliott, et al. (2007). "Low glycaemic index or low glycaemic load diets for overweight and obesity." Cochrane Database Syst Rev(3): CD005105.

Tsai, A. G. and T. A. Wadden (2006). "The evolution of very-low-calorie diets: an update and meta-analysis." Obesity (Silver Spring) 14(8): 1283-1293.

Tsigos, C., V. Hainer, et al. (2008). "Management of obesity in adults: European clinical practice guidelines." Obes Facts 1(2): 106-116. 
Tuomilehto, J., J. Lindstrom, et al. (2001). "Prevention of type 2 diabetes mellitus by changes in lifestyle among subjects with impaired glucose tolerance." N Engl J Med 344(18): 1343-1350.

Dietitians in obesity management (2007). The dietetic weight management intervention for adults in the one to one setting. Is it time for radical rethink? , DOM UK.

Valencia-Flores, M., A. Orea, et al. (2000). "Prevalence of sleep apnea and electrocardiographic disturbances in morbidly obese patients." Obes Res 8(3): 262-269.

van Hout, G. and G. van Heck (2009). "Bariatric psychology, psychological aspects of weight loss surgery." Obes Facts 2(1): 10-15.

Vetter, M. L., L. F. Faulconbridge, et al. (2010). "Behavioral and pharmacologic therapies for obesity." Nat Rev Endocrinol 6(10): 578-588.

Vuppalanchi, R. and N. Chalasani (2009). "Nonalcoholic fatty liver disease and nonalcoholic steatohepatitis: Selected practical issues in their evaluation and management." Hepatology 49(1): 306-317.

Wadden, T. A., M. L. Butryn, et al. (2007). "Lifestyle modification for the management of obesity." Gastroenterology 132(6): 2226-2238.

Wannamethee, S. G. and A. G. Shaper (1999). "Weight change and duration of overweight and obesity in the incidence of type 2 diabetes." Diabetes Care 22(8): 1266-1272.

Wee, C. C., D. B. Jones, et al. (2006). "Understanding patients' value of weight loss and expectations for bariatric surgery." Obes Surg 16(4): 496-500.

Wei, S., M. D. Schmidt, et al. (2009). "Obesity and menstrual irregularity: associations with SHBG, testosterone, and insulin." Obesity (Silver Spring) 17(5): 1070-1076.

Williams, B., N. R. Poulter, et al. (2004). "Guidelines for management of hypertension: report of the fourth working party of the British Hypertension Society, 2004-BHS IV." J Hum Hypertens 18(3): 139-185.

Williamson, D. F., J. Madans, et al. (1991). "Smoking cessation and severity of weight gain in a national cohort." N Engl J Med 324(11): 739-745.

Wilson, P. W., R. B. D'Agostino, et al. (2002). "Overweight and obesity as determinants of cardiovascular risk: the Framingham experience." Arch Intern Med 162(16): 18671872.

Wing, R. R. (2010). "Long-term effects of a lifestyle intervention on weight and cardiovascular risk factors in individuals with type 2 diabetes mellitus: four-year results of the Look AHEAD trial." Arch Intern Med 170(17): 1566-1575.

Wing, R. R. and S. Phelan (2005). "Long-term weight loss maintenance." Am J Clin Nutr 82(1 Suppl): 222S-225S.

Wise, R. A., P. L. Enright, et al. (1998). "Effect of weight gain on pulmonary function after smoking cessation in the Lung Health Study." Am J Respir Crit Care Med 157(3 Pt 1): 866-872.

Wolfe, B. L. and M. L. Terry (2006). "Expectations and outcomes with gastric bypass surgery." Obes Surg 16(12): 1622-1629.

Wolk, R., P. Berger, et al. (2003). "Body mass index: a risk factor for unstable angina and myocardial infarction in patients with angiographically confirmed coronary artery disease." Circulation 108(18): 2206-2211.

Wyatt, H. R., G. K. Grunwald, et al. (2002). "Long-term weight loss and breakfast in subjects in the National Weight Control Registry." Obes Res 10(2): 78-82.

Zoungas, S., J. Chalmers, et al. (2010). "The efficacy of lowering glycated haemoglobin with a gliclazide modified release-based intensive glucose lowering regimen in the ADVANCE trial." Diabetes Res Clin Pract 89(2): 126-133. 


\section{ADVANCED}

BARIATRIC AND

METABOLIC SURGERY

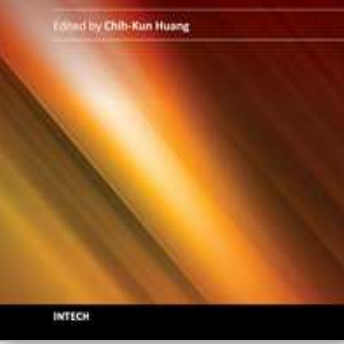

\section{Advanced Bariatric and Metabolic Surgery}

Edited by Dr. Chih-Kun Huang

ISBN 978-953-307-926-4

Hard cover, 326 pages

Publisher InTech

Published online 29, February, 2012

Published in print edition February, 2012

Bariatric surgery has gained importance in the last 20 years because of the high prevalence of global obesity, and the vast understating of the physiological and pathological aspects of obesity and associated metabolic syndromes. This book has been written by a number of highly outstanding authors and pioneering bariatric surgeons from all over the world. The intended audience for this book includes all medical professionals involved in caring for bariatric patients. The chapters cover the choice of operation, preoperative preparation including psychological aspect, postoperative care and management of complication. It also extends to concept and result of metabolic surgery and scarless bariatric surgery.

\section{How to reference}

In order to correctly reference this scholarly work, feel free to copy and paste the following:

Wen Bun Leong and Shahrad Taheri (2012). Medical Assessment and Preparation of Patients Undergoing Bariatric Surgery, Advanced Bariatric and Metabolic Surgery, Dr. Chih-Kun Huang (Ed.), ISBN: 978-953-307926-4, InTech, Available from: http://www.intechopen.com/books/advanced-bariatric-and-metabolicsurgery/medical-assessment-and-preparation-of-patients-undergoing-bariatric-surgery

\section{INTECH}

open science | open minds

\section{InTech Europe}

University Campus STeP Ri Slavka Krautzeka 83/A 51000 Rijeka, Croatia Phone: +385 (51) 770447

Fax: +385 (51) 686166 www.intechopen.com

\section{InTech China}

Unit 405, Office Block, Hotel Equatorial Shanghai No.65, Yan An Road (West), Shanghai, 200040, China 中国上海市延安西路65号上海国际贵都大饭店办公楼 405 单元 Phone: +86-21-62489820

Fax: +86-21-62489821 
(C) 2012 The Author(s). Licensee IntechOpen. This is an open access article distributed under the terms of the Creative Commons Attribution 3.0 License, which permits unrestricted use, distribution, and reproduction in any medium, provided the original work is properly cited. 